Georgia State University

ScholarWorks @ Georgia State University

$11-1-2010$

\title{
Federal Nutrition Programs and Childhood Obesity: Inside the Black Box
}

Manan Roy

Southern Methodist University

Daniel L. Millimet

Southern Methodist University \& IZA

Rusty Tchernis

Georgia State University

Follow this and additional works at: https://scholarworks.gsu.edu/uwrg_workingpapers

\section{Recommended Citation}

Roy, Manan; Millimet, Daniel L.; and Tchernis, Rusty, "Federal Nutrition Programs and Childhood Obesity: Inside the Black Box" (2010). UWRG Working Papers. 53.

https://scholarworks.gsu.edu/uwrg_workingpapers/53

This Article is brought to you for free and open access by the Usery Workplace Research Group at ScholarWorks @ Georgia State University. It has been accepted for inclusion in UWRG Working Papers by an authorized administrator of ScholarWorks @ Georgia State University. For more information, please contact scholarworks@gsu.edu. 
Working Paper 2010-11-1

November 2010

\section{Federal Nutrition Programs and Childhood Obesity: Inside the Black Box}

Manan Roy

Southern Methodist University

Daniel L. Millimet

Southern Methodist University

Rusty Tchernis

Georgia State University 


\title{
Federal Nutrition Programs and Childhood Obesity: Inside the Black Box
}

\author{
Manan Roy \\ Southern Methodist University \\ Daniel L. Millimet* \\ Southern Methodist University \& IZA \\ Rusty Tchernis \\ Georgia State University \& NBER
}

November 9, 2010

\begin{abstract}
In response to the dramatic rise in childhood obesity, particularly among low income individuals, federal nutrition assistance programs have come under scrutiny. However, the vast majority of this research focuses on the direct relationship between these programs and child health, while little is known about the mechanisms by which such relationships arise. Using the 2007 American Time Use Survey and the Eating and Health Module, we explore differences in time use across families that participate in the Supplemental Nutriation Assistance Program (SNAP), the School Breakfast Program (SBP), and the National School Lunch Program (NSLP) to better understand behavioral differences across participants and nonparticipants. These differences have important implications for future research and policy.
\end{abstract}

JEL: C31, H51, I18, I28

Keywords: School Breakfast Program, National School Lunch Program, Supplemental Nutrition Assistance Program, Time Use, Program Evaluation

* This study was conducted by Georgia State University and Southern Methodist University under a cooperative agreement with the U.S. Department of Agriculture, Economic Research Service, Food and Nutrition Assistance Research Program (agreement no. 58-5000-8-0097). The views expressed here are those of the authors and do not necessarily reflect those of the USDA or ERS. The authors wish to thank Jessica Todd, Patricia Anderson, Michael Grossman, and Ted Joyce for helpful comments. Corresponding author: Daniel L. Millimet, Department of Economics, Southern Methodist University, Box 0496, Dallas, TX 75275-0496, USA; Email: millimet@smu.edu; Tel. (214) 768-3269; Fax: (214) 768-1821. 


\section{Introduction}

The alarming rise in worldwide obesity rates, for both adults and children, over the past several decades has drawn considerable attention from the media, researchers, and policymakers. The World Health Organization places obesity among the top ten global public health issues (WHO 1998), and a 2008 nationwide U.S. poll listed obesity as the number one health problem facing children (Cawley 2010). According to Rosin (2008), the number of overweight and underweight individuals are now roughly equal, each estimated at approximately 1.1 billion worldwide. While no demographic group is immune from the epidemic, obesity is more prevalent within lower socio-economic populations (Rosin 2008; Shahar et al. 2005).

In the U.S., the prevalence of obese children has tripled in the last forty years. Data from the National Health and Nutrition Examination Survey (NHANES) I (1971-1974) and NHANES 2007-2008 indicate that the proportion of obese preschool-aged children, aged 2-5 years, increased from $5.0 \%$ to $10.4 \%$ over this time period. ${ }^{2}$ Among school-aged children, the percentage has risen from $4.0 \%$ to $19.6 \%$ for those aged $6-11 ; 6.1 \%$ to $18.1 \%$ for those aged $12-19$ years.

The health effects of obesity are well known and summarized elsewhere (e.g., Cawley 2010; U.S. White House 2010; Rosin 2008). However, two facts are worth emphasizing. First, overweight children are significantly more likely to become obese adults (Serdula et al. 1993). Second, while placing an exact dollar figure on the total medical costs, avoidable deaths, and lost productivity is extremely difficult, the figure is undoubtedly large and this burden is not born by the obese alone. Finkelstein et al. (2004) estimate that half of the $\$ 75$ billion (in 2003 dollars) in annual medical expenditure on obesity-related diseases in the U.S. is covered by Medicare and Medicaid. Moreover, diminished productivity of the labor force and higher private health insurance premiums spread the costs to the nonobese.

In light of this, a number of programs to help low income individuals, particularly children, obtain food of sufficient quantity and quality, as well as get the requisite amount of physical exercise, have been implemented. Many of these reforms have occurred within schools in a piecemeal fashion. To invigorate and centralize these efforts, President Obama established a task force on childhood obesity in February $2010 .^{3}$ Recommendations emanating from this task force have placed renewed attention on three of the largest federal nutrition programs: the Supplemental Nutrition Assistance Program (SNAP; formerly known as the Food Stamp Program), the School Breakfast Program (SBP), and the National School Lunch Program

\footnotetext{
${ }^{2}$ Obese is defined as an age- and gender-specific body mass index (BMI) greater than the $95^{t h}$ percentile based on growth charts from the Center for Disease Control (CDC). See http://www.cdc.gov/nchs/data/hestat/obesity_child_07_08/obesity_child_07_08.htm\#table1.

${ }^{3}$ See http://www . whitehouse.gov/the-press-office/presidential-memorandum-establishing-a-task-force-childhood-obesity.
} 
(NSLP). ${ }^{4}$ Given the number of households affected and potentially affected by these programs, combined with the central role these programs are poised to play in any federal efforts to combat the obesity epidemic, it is these programs upon which we focus.

These three programs have been in existence for several decades. Nonetheless, greater knowledge pertaining to their complex relationship with obesity is required. While prior studies have focused predominantly on the overall relationship between program participation and health, little is known about how or why these associations materialize, or about substitution among various factors affecting overall health. Even less is known about potential spillovers across programs when households obtain benefits from multiple programs. Assessing the importance of spillovers across programs is particularly important in light of the current child nutrition bill that has passed the Senate and could come up for vote in the House. ${ }^{5}$ The bill proposes to expand school nutrition programs by reallocating funds from SNAP.

Given this gap in knowledge, as well as the current child nutrition policy reforms being debated, our focus in this study is less on the direct association between participation in these programs and child health, and more on the possible mechanisms by which these programs may be associated with childhood obesity. Moreover, we assess the associations between participation in multiple programs and these mechanisms. Specifically, we examine behavioral differences - particularly in terms of time use - across families who participate in various combinations of SNAP, SBP, and NSLP. By doing so, we aim to dive into the black box that links program participation to child obesity.

The connection between time allocation and obesity is not well understood. Recent evidence does, however, suggest an important but complex relationship between the two. Aguiar and Hurst (2007) document changes in the U.S. pattern of time allocation over the past several decades coinciding with the sharp rise in obesity prevalence. Among adults, the authors describe the decline in time spent working (in the labor market for males and in productive household activities for females) and the rise in time spent in stationary activities. Cawley (2010) discusses the rise in maternal employment over this time period as well; see also Anderson (2010). Mullahy and Robert (2010) present evidence of a strong (positive) association between education levels and time devoted to physical activity. Betrand and Schanzenbach (2009) discuss the importance of "secondary" eating and drinking in the total time spent consuming food, as well as in total caloric intake; they find that half of all calories are consumed during other activities with this fraction being higher on higher-calorie days. Similarly, Wansik (2006) and Shiv and Fedorikhin (1999) provide evidence on the role of "mindless eating" during other activities. Anderson (2010) presents evidence on the association between children's bed time and time spent eating breakfast and obesity. Cardosa et al.

\footnotetext{
${ }^{4}$ FSP changed its name to SNAP in October 2008. For simplicity, we simply refer to SNAP throughout the paper.

${ }^{5}$ See http://www.nytimes.com/2010/09/24/us/24food.html.
} 
(2010) discuss associations between parental and child time allocations, finding significant relationships particularly for watching television. Thus, if participation in federal nutrition programs is associated with different patterns of time use within households, this has potentially important implications for thinking about how these programs may ultimately influence the obesity status of adults and children in participating households. Furthermore, if participation in multiple programs is differentially associated with time allocation, relative to participation in only individual programs, then this should guide future research into the effects of these programs as well as shed light of the expected effects of a child nutrition bill that improves one program by reallocating funds from another.

To proceed, we utilize data from the 2007 American Time Use Survey (ATUS), which also includes a companion Eating and Health (EH) Module. We begin by analyzing differences across households distinguished on the basis of their participation in SNAP, SBP, and NSLP. In particular, we are interested in differences in the detailed time allocation of individuals across households differentiated by participation status. Because respondents in the ATUS are at least 15 years old, we focus on two samples. First, we analyze the behaviors of children aged 15-18 who are still enrolled in high school. This enables us to directly examine the body mass index (BMI) of program participants, as well as their time allocation. Second, we concentrate on the characteristics of individuals between the ages of 25 and 59 with at least one child between five and 18 years old in the household. This allows us to assess the characteristics and behavior of adults residing in households that may participate in SNAP, SBP, or NSLP.

The results are striking and ought to serve as a guide to future research and policy reforms. First, successful outreach efforts and policy reforms must understand the challenges faced by households participating in federal nutrition programs. These households tend to be disadvantaged economically, be in poorer overall health, and allocate more total time to child care. Second, participating households are not homogeneous. In particular, there is a sharp contrast between low income households that participate in these programs due to the need-based subsidy component of the programs and high income households that participate in school meal programs, particularly NSLP alone, due to convenience. Third, we find strong evidence suggesting a causal beneficial effect of simultaneous participation in all three nutrition programs on adolescent BMI. Furthermore, the evidence suggests that one mechanism by which this occurs is through a greater time allocation of time by adults in these households to child care. Finally, as just alluded to, there is ample suggestive evidence of spillovers across policies; the relationship between joint participation and various behaviors is not equivalent to the "sum" of the individual relationships. While we cannot eliminate the possibility that is attributable to nonrandom selection, unlike the vast majority of the prior literature, future analyses of program effects should be extremely wary of assessing programs in isolation and policymakers should not view the programs as simple substitutes. 
The rest of the paper is organized as follows. Section 2 provides background information on the three federal nutrition assistance programs. Section 3 summarizes the existing literature. Section 4 describes the data and empirical analysis. Section 5 concludes.

\section{Background on Federal Nutrition Policy}

\subsection{Institutional Details}

Supplemental Nutrition Assistance Program The original SNAP emanated from the Great Depression and was created to provide nutritional assistance for low income families. ${ }^{6}$ This program lasted from 1939-1943 during which nearly 20 million people were served by giving participants 50 cents worth of blue stamps for every one dollar worth of orange stamps bought. Orange stamps were used to purchase any food, while blue stamps restricted purchase of only surplus food as determined by the U.S. Department of Agriculture (USDA). President Kennedy launched the next pilot SNAP in 1961. Food stamps still had to be bought under the program, but the blue stamps were abolished and a greater emphasis was placed on the consumption of perishable foods.

SNAP was made permanent by the Food Stamp Act of 1964 to aid the agriculture industry and ensure healthy food for low income families. During the early 1970s, eligibility guidelines were established, coverage of all jurisdictions in a state was required, and the USDA was permitted to cover $50 \%$ of states' administrative costs. The SNAP started to operate nationwide in 1974. In the early 1980s, several program cuts were implemented. However, concern over hunger in the late 1980s led to the elimination of sales tax on food stamps, expanded eligibility to the homeless, raised nutrition awareness, and other modifications.

Electronic Benefit Transfer (EBT) was introduced as a substitute for actual food stamps beginning in 1990. Under EBT systems, participants claim their benefits by filling out a form at a local food stamp office. After eligibility and benefit levels are ascertained, an account is created in the recipient's name and the aid is deposited electronically in the account each month. EBT is designed to reduce administrative costs, avert problems due to loss, theft or trafficking of food stamps, and reduce fraud. EBT may also help alleviate stigma associated with using paper food stamps. EBT is now mandatory.

Several changes were made to the SNAP as part of the major welfare overhaul in the mid-1990s. The Personal Responsibility and Work Opportunities Reconciliation Act of 1996 eliminated eligibility for most immigrants, regardless of legal status, placed time limits on participation for "able-bodied adults without dependents" who do not meet certain work requirements, and limited benefits. Some of these reforms, however, were relaxed in subsequent budget cycles. Finally, the USDA currently reimburses states for $50 \%$

\footnotetext{
${ }^{6}$ See http://www.fns.usda.gov/FSP/rules/Legislation/about.htm for a detailed historical account.
} 
of the administrative costs associated with approved state educational programs designed to encourage SNAP participants to make healthy food choices (so called SNAP-Ed plans).

National School Lunch Program The federal government started providing financial aid for school lunch programs in 1932, originating from various New Deal agencies such as the Federal Emergency Relief Administration, the Reconstruction Finance Corporation, and the Civil Works Administration. ${ }^{7}$ With the establishment of the Works Progress Administration and the National Youth Association, federal involvement expanded a few years later. In 1935 the process of donating surplus farm output to schools also began. With the dissolution of the New Deal agencies and a decline in farm surpluses after 1943, the continuation of the program required annual federal funds from 1943 to 1946.

The NSLP was made permanent with the National School Lunch Act in 1946. Under the act, the federal government provided financial assistance to states according to a formula based per capita income and population. The funds were then to be distributed to localities. School participation was not, nor is it today, mandatory. In 1962 the funding calculation formula was amended, basing state aid instead on the participation rate. The program was amended to allow private schools, other institutions such as child care centers, and summer programs to participate beginning in 1968.

Under the program, schools have flexibility with respect to the specific foods served, but are constrained by the fact they must operate their meal services as non-profit programs. Moreover, reimbursement of individual schools is conditional on the meals meeting federal nutritional requirements, established in 1995 under the "School Meals Initiative for Healthy Children" (SMI). For lunches, no more than $30 \%$ of the meal's calories be derived from fat, and less than $10 \%$ from saturated fat. However, lunches must provide one-third of the RDA for protein, calcium, iron, Vitamin A, Vitamin C, and an age-appropriate level of calories. In addition, all meals are recommended to reduce levels of sodium and cholesterol, as well as increase the level of dietary fiber.

Enforcement of the SMI requirements is handled by requiring states to monitor local school food authorities through reviews conducted at least once every five years. In turn, the USDA monitors state compliance with this review requirement. The USDA has also begun to provide regional and local training to ensure adequate overview. Current reform proposals center on raising the reimbursement rates per meal served, as well as tightening the nutritional requirements of meals.

\footnotetext{
${ }^{7}$ Hinrichs (2009) provides an excellent historical background of the NSLP. See also http://www.fns.usda.gov/cnd/Lunch/AboutLunch/NSLP-Program $\% 20$ History.pdf .
} 
School Breakfast Program The SBP is the youngest of the three programs, founded initially in the Child Nutrition Act of 1966. The pilot version created in 1966 provided grants to states to help schools provide breakfast to "nutritionally needy" children. ${ }^{8}$ The program's main goal was to aid schools serving poor areas or children traveling a long distance to attend school. To incentivize schools in poor areas to participate, federal payments for schools deemed to be in "severe need" areas were higher than elsewhere.

The program went through several extensions and modifications, becoming a permanent program starting in 1975. Starting in 1973, reimbursements were calculated on a per meal basis. Since 1995, as under the NSLP, reimbursement of schools is governed by the SMI. As with lunches, no more than $30 \%$ of a breakfast's calories be derived from fat, and less than $10 \%$ from saturated fat. Breakfasts also must provide one-fourth of the Recommended Dietary Allowance (RDA) for protein, calcium, iron, Vitamin A, Vitamin $\mathrm{C}$, and contain an age-appropriate level of calories. Finally, as with NSLP, current reform proposals center on increasing the reimbursement rates per meal served and revising the nutritional requirements of meals.

\subsection{Participation and Cost}

Supplemental Nutrition Assistance Program To be eligible for SNAP benefits, a household without elderly or disabled members must have a gross income below $130 \%$ of the federal poverty line, and all households must have a net income below $100 \%$ of the federal poverty line. In addition, households are required to have no more than $\$ 2,000$ in liquid assets such as a bank account. Households with at least one disabled or elderly member may also have no more than $\$ 3,000$ in countable assets. Under SNAP rules, a household is defined as an individual or a group of people, not necessarily related, who live, buy, and cook meals together.

Eligibility also depends on some non-financial attributes. For instance, "able-bodied adults without dependents" who are not working at least 20 hours per week or participating in a training program are eligible to receive a maximum of three months of benefits over a 36 month period. ${ }^{9}$ In addition, adult immigrants that have been in the U.S. less than five years are not eligible. However, all legal child immigrants are eligible and eligible household members are entitled to benefits even if other household members are ineligible.

Participation in the SNAP rose steadily from 2.9 million individuals in 1969 to 27.5 million in $1994{ }^{10}$ Following welfare reform in 1996, the number of participants declined to 17.3 million in 2001, roughly the same as in 1979. Between the relaxation in eligibility requirements in 2002 and the current economic

\footnotetext{
${ }^{8}$ See http://www.fns.usda.gov/cnd/breakfast/AboutBFast/ProgHistory.htm

${ }^{9}$ See http://www.fns.usda.gov/FSP/rules/Legislation/about.htm.

${ }^{10}$ See http://www.fns. usda.gov/pd/SNAPsummary.htm .
} 
crisis, however, the number of participants has risen to an all-time high. In 2009, there were 33.7 million participants distributed among 15.2 million households. In June 2010, participation rose to over 41.2 million individuals, representing approximately one in eight Americans. ${ }^{11}$

In 2009 , the average monthly benefit per person was $\$ 124.45$, which amounts to approximately $\$ 1.40$ per meal. The total cost to the federal government was over $\$ 53$ billion. This is up from roughly $\$ 37$ billion in the prior year, and $\$ 35$ billion in 1994 (in 2009 dollars).

School Nutrition Programs Eligibility criteria are identical for the SBP and NSLP. All schools are eligible to participate in both programs, but none are required to do so unless there is a state mandate. Moreover, schools participating in one program are not required to participate in the other. Every child attending a participating schools can purchase meals through the programs. However, households are eligible for free or reduced price meals based on need. To qualify for free meals, household income cannot exceed $130 \%$ of the federal poverty line; reduced price meals are available to children from households with income between $130 \%$ and $185 \%$ of the federal poverty line. The same application process encompasses both the SBP and the NSLP and eligible students apply directly to the school. Moreover, children whose families receive aid under either the SNAP, TANF, or the Food Distribution Program on Indian Reservations are automatically eligible for free meals. The current child nutrition bill moving from the Senate to the House extends free meals to Medicaid recipients as well without requiring additional paperwork.

Participation in the SBP has grown rapidly, but still lags behind participation in the NSLP. In 1970, 0.5 million children participated in the SBP on an average school day. This has grown to 11.1 million in 2009, with 9.1 million qualifying for free or reduced price breakfast. ${ }^{12}$ Participation in the NSLP exceeded seven million in its first year of permanent existence, 1946. In 2009, the NSLP provided lunch to over 31 million children on an average school day, roughly 19.3 million qualifying for free or reduced price meals.

For the 2010-2011 school year, schools are reimbursed by the federal government $\$ 2.72(\$ 2.74)$ per free lunch, $\$ 2.32(\$ 2.34)$ per reduced price lunch, and $\$ 0.26(\$ 0.28)$ per full price lunch in non-severe (severe) need areas. ${ }^{13}$ Under the SBP, schools are reimbursed by the federal government $\$ 1.48(\$ 1.76)$ per free breakfast, $\$ 1.18$ (\$1.46) per reduced price breakfast, and $\$ 0.26(\$ 0.26)$ per full price breakfast in

\footnotetext{
${ }^{11}$ See http://www.fns.usda.gov/fns/key_data/june-2010.pdf.

${ }^{12}$ The facts reported here may be found at http://www.fns.usda.gov/cnd/Breakfast/AboutBFast/SBPFactSheet.pdf and

http://www.fns.usda.gov/cnd/lunch/AboutLunch/NSLPFactSheet.pdf and http://www.fns.usda.gov/fns/key_data/june-2010.pdf.

${ }^{13}$ For lunch, severe need means that more than $60 \%$ of students qualified for free or reduced price lunches two years prior. Reimbursement rates apply only to the 48 contiguous states; rates are higher for Alaska and Hawaii. See http://www.fns.usda.gov/cnd/Governance/notices/naps/NAPs10-11.pdf.
} 
non-severe (severe) need areas. ${ }^{14}$ Schools set prices for full price meals, but students may be charged no more than $\$ 0.40$ (\$0.30) for a reduced price lunch (breakfast). The total cost of the SBP to the federal government in Fiscal Year 2009 was $\$ 2.6$ billion; the corresponding cost for the NSLP was $\$ 9.8$ billion.

\subsection{Current State of Federal Nutrition Programs}

The State of School Nutrition 2009, while being primarily concerned with the cost of and funding for food for the various programs, paints an optimistic picture of the SBP and NSLP in terms of their contribution to the health and nutritional education of participating children. ${ }^{15}$ The report indicates a marked increase in the availability of healthy options, such as vegetarian offerings and low fat prepared/packaged foods, with respective gains of $12.4 \%$ and $11.5 \%$ (since 2007). This national survey of 1,207 school nutrition directors from 49 states shows that the current economic downturn has not hindered the availability of healthy school meals, nor adversely impacted educational efforts centered on making healthy food choices. Some examples illustrate the gains: $99 \%$ of districts provided fat-free or low-fat milk, $98.8 \%$ provided fresh fruits and vegetables, $96.3 \%$ provided whole grain items, and $63.9 \%$ provided vegetarian meals. Additionally, $78 \%$ of the districts allow parents to supervise or control the purchases made by the students.

Despite this rosy assessment, the USDA-sponsored Third School Nutrition Dietary Assessment Study (SNDA-III) enumerates several areas that need immediate and greater attention. SNDA-III uses a nationally representative sample of 130 public School Food Authorities comprising 398 schools, along with 2,314 public school students in grades 1-12 in 287 of these schools. The study focuses on the school food environment and students' dietary behaviors.

The findings indicate that schools need to better control access to high calorie, low nutrient foods to make school meals even healthier. ${ }^{16}$ While most of the schools participating in the SBP and NSLP serve meals that satisfy the SMI requirements for protein, vitamins A and C, calcium and iron, the levels of fat and saturated fat failed to meet SMI standards for lunch (breakfast) in over two-thirds (one-third) of schools. In addition, the sodium content of lunches exceeded the recommended target more often than breakfasts. However, roughly $90 \%$ of schools offered the opportunity to select a breakfast or lunch fully compliant with the SMI. Finally, the SNDA-III highlighted the presence of "competitive foods," particularly through vending machines in secondary school, as a threat to undo healthy gains obtained under the NSLP and SBP. Despite these difficulties in meeting current standards, the process has already begun to revise

\footnotetext{
${ }^{14}$ For breakfast, severe need means that more than $40 \%$ of students qualified for free or reduced price lunches two years prior. As with lunch, reimbursement rates apply only to the 48 contiguous states; rates are higher for Alaska and Hawaii. See http://www.fns.usda.gov/cnd/Governance/notices/naps/NAPs10-11.pdf.

${ }^{15}$ See http: //www. schoolnutrition.org/Blog. aspx?id=12832\&blogid=564

${ }^{16}$ See http://www.fns.usda.gov/ora/menu/Published/CNP/FILES/SNDAIII-Vol1ExecSum.pdf .
} 
the nutrition standards implemented under the SMI (Stallings and Taylor 2008).

In terms of the SNAP, it is well known that even though benefits can only be used on food, there is no guarantee that such subsidies will increase the total intake of food if the benefits constitute an infra-marginal subsidy (i.e., the subsidy is less than would otherwise be spent on food in the absence of the program). As such, the benefit is no different theoretically from a pure income transfer. However, in practice, households may treat SNAP income differently from other sources of income, thereby allocating more resources to food consumption. Regardless of whether SNAP benefits are treated differently from other income, SNAP may influence the type of food consumed due both to the income effect from participation and the fact that food eligible for use with SNAP benefits comprise fruits and vegetables, grain products, meats, fish, poultry, and dairy products. ${ }^{17}$ Recently, the Food, Nutrition and Conservation Act of 2008 allocated $\$ 20$ million to the Healthy Incentives Pilot (HIP). The goal of the HIP is to ascertain the efficacy of incentives to consume greater quantities of fruits, vegetables, or other nutritious foods. ${ }^{18}$ The USDA is also attempting to expand the number of farmers' markets licensed to accept SNAP benefits.

\section{$3 \quad$ Literature Review}

\subsection{Program Participation and Health}

Supplemental Nutrition Assistance Program Existing research on the link between SNAP participation and obesity is mixed. Ver Ploeg et al. (2006) argues that food stamps are not the driving force behind the increase in obesity for women; the probability of being overweight and average BMI were highest among SNAP participants during the period 1976-1980, but increased the least for female SNAP participants compared to eligible non-participants, as well as moderate and high income women, over the period 1976-2002. However, the relationships for men were reversed. Male SNAP participants had lower BMI on average and lower rates of being overweight in the late 1970s. These gaps have now been virtually eliminated.

Despite these trends, most studies, however, find a positive and significant association between SNAP participation and the probability of being overweight for women, but not men. Using panel data techniques and information on state-level SNAP, Meyerhoefer and Pylypchuk (2008) find that program participation by women is associated with higher medical expenditures and a $5.9 \%$ increase in their likelihood of being overweight and obese. While smaller than previous estimates, like that in Gibson (2003) and Townsend et al. (2001), these figures are nonetheless economically significant. Chen et al. (2005) confirms the absence

\footnotetext{
${ }^{17}$ See http://www.fns.usda.gov/SNAP/retailers/eligible.ht.

${ }^{18}$ See http://www.fns.usda.gov/snap/HIP/default.htm.
} 
of an association between SNAP participation and weight for adult men and a positive association for adult women. The authors conclude that women belong to the so-called "distorted" group who spend all of their SNAP benefits on food (Whitmore 2002; Wilde and Andrews 2000). Since their energy consumption tends to be lower than that of men, their weight gain is more dramatic.

Focusing on food purchases, Besharov $(2002,2003)$ suggest that the non-cash form of the SNAP benefit, combined with the benefit constituting a non-infra-marginal subsidy for many, has led to greater caloric consumption by low income recipients; recipients purchase more food on average than they would otherwise buy. Fox et al. (2004) report an average increase in total food expenditures by $\$ 0.17-\$ 0.47$ for every dollar of SNAP benefits. Breunig and Dasgupta (2005) suggest that the greater propensity to buy food out of food stamps results from the varying distribution of resources between men and women within a household. Whereas the authors find no empirical evidence that single-adult households treat food stamp income differently from cash, they do find evidence of a difference in multiple adult households. More recently, Hoynes and Schanzenbach (2009) find no difference in the effect of an extra dollar of income or an extra dollar in food stamps on total food expenditures, although they do find that participants increase their total food expenditure due to the income effect of participation.

Cole and Fox (2008) use data from the NHANES 1999-2004 to compare differences between three groups of individuals: SNAP participants, income-eligible non-participants, and income-ineligible nonparticipants. The authors find that SNAP participants and income-eligible non-participants are similar in their intake of minerals, vitamins and macronutrients, but their consumption lagged behind higher income individuals. Moreover, SNAP participants relied more on the consumption of solid fats, alcoholic beverages, and added sugars for their energy compared to eligible non-participants and higher income individuals. Consonant with previous studies, female SNAP recipients are more likely to have an unhealthy BMI relative to women in the other two groups. Moreover, the diets of all groups failed to satisfy the Dietary Guidelines for Americans, and all of them demonstrated very low intakes of whole grains, dark green and orange vegetables, and legumes. Adults in both low income groups - participants and income-eligible non-participants - had much lower probability of consuming foods from eight out of ten food groups, while children exhibited fewer differences.

On the other hand, Kaushal (2007) exploits the modifications in the immigrant eligibility criteria for food stamps that occurred under the 1996 welfare reform as a natural experiment to examine the effect of food stamps on the BMI of immigrant adults. Her results suggest that less educated, unmarried immigrant mothers utilize food stamps by 10 percentage points more in states with substitute programs in the post-1996 period compared to states that exercised the federal ban. However, this increase in SNAP participation was not associated with any statistically significant difference in BMI. More recently, Kreider 
et al. (2009) find beneficial effects of SNAP participation on children using a nonparametric bounding approach.

School Nutrition Programs Early analysis of school nutrition programs occurred in the 1990s with a series of studies utilizing the 1992 School Nutrition Dietary Assessment (SNDA-1) study. Gleason (1995) finds that SBP availability is not associated with a higher probability of eating breakfast. Moreover, the author finds that lunches provided under the NSLP derived an average of $38 \%$ of food energy from fat, exceeding guidelines. Burghardt et al. (1995) report that meals provided under the NSLP exceeded guidelines for total and saturated fat and sodium, whereas meals provided under the SBP exceeded guidelines for saturated fat and cholesterol. Gordon et al. (1995) use 24-hour dietary recall data and conclude that both SBP and NSLP participation are associated with higher intake of fat and saturated fat, but also some nutrients.

More recently, Gleason and Suitor (2003) use two nonconsecutive days of 24-hour dietary recall data to obtain fixed effects estimates of NSLP participation. The authors find that NSLP participation increases intake of nutrients, but also increases intake of dietary fat. Hofferth and Curtin (2005) find no association between SBP participation and the probability of being overweight after controlling for NSLP participation. In addition, instrumental variables estimates indicate no impact of NSLP participation. Dunifon and Kowaleski-Jones (2003) use sibling fixed effects models to analyze the effect of NSLP participation on child well-being, finding no evidence of beneficial effects. Bhattacharya et al. (2006) analyze the effects of SBP availability in the school on nutritional intake using NHANES III. The authors compare child outcomes in-school versus out-of-school periods in schools participating and not participating in the SBP, concluding that SBP availability "has no effect on the total number of calories consumed or on the probability that a child eats breakfast, but it improves the nutritional quality of the diet substantially" (p. 447). Schanzenbach (2009) utilizes panel data methods, as well as a regression discontinuity approach that exploits the sharp income cut-off for eligibility for reduced-price meals, to assess the impact of the NSLP. She finds that NSLP participation increases the probability of being obese due to the additional calories provided by school lunches. Millimet et al. (2010) assess the relationship between participation in both SBP and NSLP and child weight. Their results are suggestive of a beneficial impact of SBP participation, but a detrimental effect of NSLP participation.

Finally, a few studies offer less direct evidence of the possible effects of the SBP and NSLP. For instance, Long (1991) finds that one dollar of NSLP (SBP) benefits displaces only $\$ 0.60$ (none) of household food expenditures. Thus, both programs increase the total value of food consumed by the household. von Hippel et al. (2007) show that children are more at-risk of gaining weight during summer vacation than during 
the school-year. While this is potentially attributable to children's propensity to consume more food while at home, it could also be explained by the lack of access to school meal programs during the summer for non-summer school attendees. Hinrichs (2010) estimates the long-run effects of participation in NSLP at its inception on health as adults and educational outcomes. To isolate the effects of the participation in the NSLP from the possibly confounding influences of other federal programs like SBP, SNAP and WIC that came into existence much later, the author focuses on data from 1947. He finds that childhood participation in NSLP either had no long-run health effects or the short-term health benefits eroded over time.

Prior to continuing, it is noteworthy that the majority of the prior literature on the SNAP, SBP, and NSLP, focus on one of these programs in isolation. A notable exception that analyzes individual as well as joint participation in all three programs is Jones et al. (2003). Their results suggest that participating girls are at a lower risk of being overweight relative to non-participants, as are boys in food insecure households. However, there is little statistical difference between participation in SNAP and SNAP combined with SBP and NSLP.

\subsection{Time Use and Child Health}

Aside from the literature on federal nutrition assistance programs, there is an extensive literature focusing on household time allocation and child health. Probably the most oft-studied issue is the relationship between maternal employment and child obesity. Anderson et al. (2003) find that a child's probability of being overweight is increasing in the mother's work intensity over the child's life. This is especially true for higher socioeconomic groups. Cawley and Liu (2007), in a study similar in spirit to ours, utilize the 2003-2006 ATUS to assess the impact of maternal employment on child weight operating through the mother's allocation of time to child-related activities such as diet and exercise. Their estimates suggest that employed women spend substantially less time with their children, in particular time spent on cooking, eating, and playing with children. They also demonstrate that working mothers have higher propensity to purchase prepared meals. These findings provide a causal mechanism by which maternal employment and childhood obesity are linked. Anderson (2010) is also similar in spirit to our study and finds that type of child care, children's bed time, and a regular eating time for breakfast are important correlates of child weight, but do not explain the association between maternal employment and child obesity.

Fertig et al. (2009) also focus on the channels through which maternal employment may influence childhood obesity. Using time diaries and interview responses, the authors find that supervisory and nutrition-related activities play significant, albeit small roles, in the connection between maternal employment and childhood obesity. For more educated mothers, working longer hours is associated with more time watching TV by children, increasing BMI. However, for less educated mothers, longer working hours 
are associated with children staying in school longer, thereby reducing their BMI. Interestingly, for both education groups, longer working hours by the mother are associated with fewer meals consumed by children

- likely skipping breakfast - with deleterious consequences for children's BMI.

Kalenkoski and Stratton (2008) use the 2006 ATUS to analyze the linkage between eating and sleeping habits, as well as the intensity of physical activity, and adults' weight status. Not surprisingly, their results suggest that men who eat out more and both men and women who are mostly engaged in sedentary activities have distinctly higher BMI. Women involved in activities requiring high energy expenditure have significantly lower BMI, although demographic factors continue to be important. More recently, Hamermesh (2009) uses the 2007 ATUS and finds that BMI is negatively associated with the number of primary meals, but not significantly associated with the time spent eating. Bertrand and Schanzenbach (2009) document a positive association between the share of calories consumed during secondary activities and total calories consumed in a day.

Other strands of the literature focus on the role of extracurricular activities and neighborhood environment. For example, while Elkins et al. (2004) find that after-school sports provide a viable mechanism through which adolescent obesity may be prevented. Liu et al. (2006) find that living in greener neighborhoods is associated with reduced risk of being overweight, while greater distance from supermarkets causes an increase in the risk of being overweight.

\section{Empirics}

Despite this vast literature on the roles of federal nutrition assistance programs and various individual behaviors that may contribute to the childhood obesity epidemic, there is little empirical analysis bridging these two strands of research. To begin to address this gap, we present an exploratory analysis of the differences in time use patterns between participants and non-participants.

\subsection{Data}

The data come from the 2007 wave of the ATUS and the associated EH module provided by the U.S. Bureau of Labor Statistics. Subjects were drawn from households in their last month of participation in the Current Population Survey (CPS). One respondent age 15 or older was randomly selected from each household and asked to describe his or her primary activities during the preceding 24-hour period. Specially coded time diaries - including information on the duration and location of each activity - were 
constructed from these responses. ${ }^{19}$ The CPS and ATUS also provide a wide array of demographic and economic information on age, gender, race, ethnicity, state of residence, education, household income, and family composition.

Since we are interested in evaluating differences in time allocation by participation status in SNAP, SBP and NSLP, the EH module is especially useful as it provides information on participation in federal nutrition assistance programs. ${ }^{20}$ We define five program participation variables:

- SNAP: equals one if the respondent or any other household member received food stamp benefits within 30 days of the day of the survey and does not have children participating in SBP or NSLP, and zero otherwise;

- NSLP: equals one if the respondent has at least one child in his/her household who reports eating a school-prepared and provided lunch and does not have a child participating in SBP nor any household member receiving food stamp benefits, and zero otherwise;

- SNAP \& NSLP: equals one if the respondent or any other household member received food stamp benefits within 30 days of the day of the survey and if the respondent has at least one child in his/her household who reports eating a school-prepared and provided lunch and does not have a child participating in SBP, and zero otherwise;

- SMEAL: equals one if the respondent has at least one child in his/her household who reports eating a school-prepared and provided breakfast and lunch and does not report any household member receiving food stamp benefits, and zero otherwise;

- ALL: equals one if respondent's answer is in the affirmative for all the three Programs.

Thus, the categories are defined such that they are mutually exclusive and the omitted category is no

\footnotetext{
${ }^{19}$ While the ATUS provides information on activities listed as primary activities in the time-diary, individuals sometimes multitask and this information is not recorded by the ATUS.

${ }^{20}$ Specifically, we use the answers to three questions posed to the respondent:

1. In the past week, did any of your household children under the age of 19 eat a breakfast that was prepared and served at a school, a paid day care provider, a Head Start center, or a summer day program?

2. In the past week, did any of your household children under the age of 19 eat a lunch that was prepared and served at a school, a paid day care provider, a Head Start center, or a summer day program?
}

3. In the past 30 days, did you or anyone in your household get food stamp benefits? 
participation in any of the programs. ${ }^{21}$ The EH module also provides the respondent's weight and height.

In the analysis below we focus on two distinct samples. Our first sample comprises respondents aged 25-59 with at least one child between five and 18 years old since only households with children in school have access to school nutrition programs. We also examine two sub-samples of this first sample: respondents with at least one child between five and ten years old for comparison, and to respondents from households with a combined income of less than $\$ 75,000$. Our second sample includes respondents aged 15-18 who are still enrolled in school. This sample allows to assess the behavior of the teenagers directly affected by school meal programs.

\subsection{Methodology \& Findings}

Our analysis is divided into two parts. First, we provide descriptive statistics for time allocation and other family characteristics across households defined on the basis of program participation. ${ }^{22}$ Second, we use various multivariate models to assess the associations between program participation and BMI (in logs and percentiles) of teenagers and program participation and time allocation of teenagers and adults. Given the possibility of non-random selection into the programs - and the inadequacy of the ATUS data in terms of offering a clear identification strategy of causal effects - any differences highlighted in our analysis are not meant to be given a causal interpretation. Nonetheless, the findings are informative given the dearth of knowledge on differences in behavior by participation status. Moreover, by shedding some light on possible mechanisms by which federal nutrition assistance programs may affect the health of participants, such information should prove useful to policymakers, especially designers of nutrition education programs.

\subsubsection{Descriptive Statistics}

Table 1 reports the summary statistics for respondents aged 25-59 with at least one child between five and 18 years old. The total sample size is 3,793, with 1,406 participating in no program, 1,399 (686) participating in NSLP only (NSLP and SBP), and 75 (57) participating in SNAP only (SNAP and NSLP). In addition to providing means and standard deviations in each table, we report the results from tests of equal means across each column and the final column, representing no participation in any program. The variables contained in the tables are divided into four blocks: time allocation, health measures, economic attributes, and demographic characteristics. To be clear, note that the summary statistics relate to adult respondents (aged 25-59) across households where some member may or may not participate in SNAP and

\footnotetext{
${ }^{21}$ Note, nearly all students who participate in SBP also participate in NSLP. Thus, we do not consider seperate categories for SBP alone or SBP and SNAP but not NSLP.

${ }^{22}$ All results reported are weighted by sample weights provided in the EH module.
} 
where a household child may or may not participate in school meal programs.

The first several time categories relate to eating, drinking, and food preparation. Respondents in households with members participating in all three programs spend significantly less time in primary eating and drinking (14 minutes fewer), and marginally less time in secondary drinking (two minutes), relative to households participating in no program. Interestingly, this same pattern holds across most households participating in only a subset of the three programs except households only participating in the NSLP, the program Millimet et al. (2010) and Schanzenbach (2009) find contributes to childhood obesity. Here, respondents spend more time in primary eating and drinking (albeit not statistically significant) and significantly more time in secondary drinking (ten minutes more). The lack of a strong association between participation and secondary eating and drinking is also quite noteworthy. In light of the results in Betrand and Schanzenbach (2009) highlighting the importance of secondary eating and drinking in total caloric intake, the fact that secondary eating and drinking is just as prevalent among program participants as nonparticipants suggests that future educational efforts designed to promote healthy living may prove more successful by focusing on "mindless eating" in addition to making healthy food choices.

In terms of food preparation and purchasing, respondents in households with at least one participant in both SBP and NSLP spend significantly less time grocery shopping. In fact, all categories of participants spend less time on average grocery shopping than respondents residing in households that participate in none of the programs (although the differences are not statistically significant). Similarly, all categories of participants spend less time on average engaged in travel time related to grocery shopping than respondents residing in households that participate in none of the programs (although the difference continues to be statistically significant only for participants in both SBP and NSLP). However, restricting the sample to respondents that report strictly positive time allocated to grocery shopping, we find that respondents in households participating in SNAP and NSLP spend the most time shopping for groceries (nearly 48 minutes), followed by respondents participating in all three programs (almost 42 minutes). Respondents in households not participating in any programs spend less than 40 minutes on grocery shopping conditional on a non-zero time allocation. Travel time for grocery shopping conditional on a positive time allocation follows a similar pattern. Participants in SNAP only, SNAP and NSLP, or all three programs spend the most time (63 minutes), whereas participants in no programs spend less than one hour. Participants in SBP and NSLP only spend the least amount of travel time (conditional on a positive amount), devoting on average less than 53 minutes.

This is interesting in light of the recent attention given researchers and President Obama's obesity task force to so-called "food deserts" (i.e., the notion that low income households have less immediate access to 
chain supermarkets and quality restaurants). ${ }^{23}$ The fact that households participating in federal nutrition programs spend more time on grocery shopping conditional on spending some time - and are more likely to not spend any time shopping for groceries - is at least suggestive of the presence of such a phenomenon.

Respondents in households participating in all three programs spend significantly less time purchasing non-grocery food items. Finally, respondents in households participating in NSLP and SNAP allocate significantly more time to food preparation (almost 16 minutes), while participants in SBP and NSLP spend significantly less (albeit only two minutes fewer).

Time spent on food preparation is an important mechanism by which participation may ultimately affect health since changes in food technology have enabled the consumption of more calories in less time using pre-packaged, calorie dense food items (Cawley 2010). Thus, it is striking that participation in both SNAP and NSLP is associated with more time in food preparation (despite less time spent in primary or secondary eating or drinking). However, participation in NSLP or SNAP in isolation is not associated with any change in time allocated to food preparation (relative to no participation in any program). The fact that joint participation matters is consistent with the presence of important spillovers across programs, as well as calls into question the logic of the current child nutrition bill which seeks to expand one program at the expense of the other.

The next set of time categories relate to own personal care and caring for other household members, including children. Respondents in households participating in SBP and NSLP spend significantly more time on own personal care (an additional eleven minutes). Respondents in households participating in all three programs spend significantly more time caring for children in the household (15 minutes more). The difference is smaller, but still statistically significant, for respondents in households with someone participating only in NSLP or NSLP and SBP. When it comes to allocating time to child health, however, respondents in households that participate in SNAP only or SNAP and NSLP allocate significantly less; respondents in NSLP only households also report less time devoted to child health, although the difference is not statistically significant. If this time difference reflects children in participant households being healthier, then this lower time allocation is to be expected. However, if the difference arises due to fewer wellness visits to the pediatrician or non-response to child illness, then this suggests that bundling outreach programs related to child health with educational efforts undertaken as part of SBP, NSLP, and SNAP may prove effective.

In terms of the remaining time allocations, we find that SNAP participation (whether or not in combination with school meal programs), as well as SBP and NSLP participation without SNAP, are associated with significantly less time devoted by the respondent to sports, recreation, and exercise (both partici-

\footnotetext{
${ }^{23}$ See, e.g., Liu et al. (2006) and Bitler and Haider (2010) and the references cited.
} 
pating and observing). In addition, respondents in all categories of program participation spend more time watching television and movies (15 minutes more for respondents in households participating in all three programs). Thus, future bundling of program participation with education regarding the benefits of exercise and reductions in television watching is suggested.

The next set of variables relate to the health of the respondent. Strikingly, respondents in each category associated with program participation have a significantly higher average weight, BMI (except NSLP only), and likelihood of obesity. This is, perhaps, not overly surprising since obesity is more prevalent among low-income individuals. In addition, respondents in nearly each participation category report higher rates of poor, fair, or good health status and lower rates of very good or excellent health status. For example, respondents in households participating in all three programs are $18 \%$ more likely to report being in poor or fair health and $32 \%$ less likely to report being in very good or excellent health.

The final variables relate to the socio-economic attributes of the survey respondents. In terms of labor market participation, we find that SNAP participation (whether or not in combination with school meal programs) is associated with lower labor market attachment by both the respondent and his or her spouse. This lower attachment manifests itself not just in the probability of being employed, but also the average number of hours worked conditional on being employed. Note, this alone does not explain the higher time allocation to food preparation discussed above since that only occurred for participants in both SNAP and NSLP. On the other hand, participants in school meal programs only (either NSLP alone or both SBP and NSLP) tend to have slightly greater labor force attachments. For example, respondents in households that participate in both school meal programs are more likely to work full-time and less likely to work part-time or be out of the labor force; respondents in households that participate in NSLP only are more likely have an employed spouse. Again, this suggests possible policy reforms where outreach efforts associated with school meal programs focus strongly on food choices in the home. Since participants in NSLP are more likely to reside in households with two working adults, educational programs need to focus on healthy, but time feasible, options.

Not surprisingly, there are also large differences in household income across participation categories. Given the institutional rules governing participation, SNAP participation (whether or not in combination with school meal programs) is associated with the lowest income categories. ${ }^{24}$ For instance, almost $53 \%$ of households participating in all three programs have a household income less than $\$ 15,000$. On the other

\footnotetext{
${ }^{24}$ Note, however, that four respondents in our sample report participation in SNAP - either in isolation or with NSLP along with a household income greater than $\$ 75,000$. Most likely this is indicate of measurement error in one of the variables. In the entire ATUS sample, there are 799 respondents that report participation in SNAP; 15 (or 0.88\%) also report a household income greater than $\$ 75,000$.
} 
hand, participation in NSLP only is associated with the highest income households; $43 \%$ of households report an income greater than $\$ 75,000$. Finally, participants in both school meal programs tend to be poorer than those participating in no programs, but better off than households participating in SNAP. The fact that participants in NSLP only reside in the highest income households on average suggests, in accordance with the results above on employment status, that many households with two working adults rely on school lunches due to the absence of time to pack lunches. Thus, efforts to improve the nutrition choices made at home must account for the time constraints faced by households with two working adults.

Turning to the remaining attributes, a few noteworthy differences arise. First, except for households participating only in NSLP, respondents are significantly less likely to be white, slightly less likely to be Asian, significantly more likely to be black, and modestly more likely to be Hispanic. Second, again except for households participating only in NSLP, respondents are significantly more likely to be unmarried. This is particularly relevant since the challenges of maintaining a healthy lifestyle for one's self and children are presumably much different in single parent households versus multiple adult households. Understanding and overcoming these obstacles ought to be a focus of any policy designed to combat childhood obesity. Third, the association between the various program participation categories and education roughly mirrors the association between program participation and income. Finally, across all program participation categories, relative to nonparticipants, households tend to be larger due to more children and the age of the youngest child tends to be lower.

The data assessed here, despite being purely descriptive, brings three important facets of the relationship between federal nutrition programs and child health to light. First, successful outreach efforts and policy reforms must understand the challenges faced by households participating in federal nutrition programs (e.g., low income, lower labor force attachment, perhaps a greater likelihood of residing in a "food desert," and greater time demands in terms of child care). Second, participating households are not homogeneous. In fact, there appears to be a sharp contrast between low income households that participate in these programs due to the need-based subsidy component of the programs and high income households that participate in school meal programs, particularly NSLP, due to convenience. Finally, even when examining the descriptive evidence, there is strong evidence suggesting important spillovers across policies. Thus, unlike the vast majority of the prior literature, analyses of program effects should not consider programs in isolation. 


\subsubsection{Multivariate Analysis}

Adolescent Sample Turning to the regression analysis, we begin by analyzing the relationship between program participation and the body mass index (BMI) and time allocation of adolescent respondents. ${ }^{25}$ Results are displayed in Tables 2 and 3. Restricting the sample to children age 15-18, still in school, and with non-missing data on BMI, age, and gender reduces the sample to 522 observations. ${ }^{26}$ For each specification, the results of two hypothesis tests are provided at the bottom of the tables. First, we test the null that coefficients on the four program variables are jointly equal to zero. Second, we test whether the coefficient on the treatment ALL is equal to the sum of the coefficients on SMEAL and SNAP. Given the definitions of the four program variables, this amounts to a test of whether the relationship between participating in all three programs and health is equal to the sum of the separate relationships. In other words, rejection of the null suggests that the association between participating in all three programs is not simply additive. While rejecting such a hypothesis could be attributable to selection, researchers should be avoid assuming there are no spillovers from participating in multiple programs without careful consideration.

Table 2 utilizes two measures of adolescent weight: log BMI and BMI percentile. In addition, three specifications are estimated. Model I only includes the four participation variables. Model II adds individuallevel controls. Model III adds controls for parental education. In all cases, we fail to reject the null that the four coefficients are jointly equal to zero. However, in all cases we do reject the null that there are no spillover effects from multiple program participation at at least the $p<0.10$ confidence level. This is a striking result. For example, examining Model III using BMI in logs, we find that the coefficients on SNAP, SBP, and NSLP are each positive, but individually insignificant at conventional statistical levels. If one estimated the effect of participating in all three programs by simply summing the coefficients on SMEAL and SNAP, one would obtain a point estimate of 0.092 (i.e., simultaneous participation is associated with a $9.6 \%$ increase in BMI). ${ }^{27}$ However, by directly estimating the association between BMI and participation in all three programs, we obtain a statistically significant point estimate of -0.126 (i.e., simultaneous participation is associated with a $11.8 \%$ decrease in BMI). This suggests that, first and foremost, researchers ought to be very cautious drawing conclusions from models incorporating participation in various social programs in isolation. The relationship between joint participation is not simply the sum of the individual program relationships; multiple program participation should be treated statistically as

\footnotetext{
${ }^{25} \mathrm{BMI}$ is defined as body weight in kilograms divided by height in meters squared.

${ }^{26}$ No adolescent respondents report participating in SNAP and NSLP but not SBP. Hence, this treatment category is omitted.

${ }^{27}$ The association in percentage terms is computed as $\exp \left(\beta_{S M E A L}+\beta_{S N A P}\right)-1$.
} 
a unique treatment or policy. Second, and more directly, this result indicates that participation in all three programs by adolescents in low-income households is associated with a statistically and economically significant reduction in BMI. Again, while this should not be interpreted as a causal relationship, in light of the fact that obesity is more prevalent in low-income and minority households - exactly the households from Table 1 that are more likely to participate in all three programs - one would suspect positive selection into the ALL treatment (Wang and Beydoun 2007). If this indeed the case, then it is quite likely that the true causal effect of participating in all three programs is even more beneficial than suggested by the partial correlation.

Table 3 presents the results from OLS models using various time allocations. ${ }^{28}$ We examine time spent on primary eating and drinking, secondary eating, secondary drinking, personal care, and watching television and movies. The control set is identical to Model III in Table 2. To start, note that we reject the null that the four coefficients of interest are jointly equal to zero at the $p<0.10$ confidence level only for watching television and movies. In addition, we reject the null that there are no spillover effects from multiple program participation at the $p<0.10$ confidence level for two of the five time categories: primary eating and drinking and watching television and movies.

In terms of the individual coefficient estimates, we find a negative relationship between NSLP (eight minutes less), SMEAL (twelve minutes less), and SNAP (eleven minutes less) and time spent on primary eating and drinking; however, only the coefficient on SMEAL is statistically significant at conventional levels. Since these same program categories are associated with higher BMI in Table 2 (albeit statistically insignificant), this suggests that adolescents in these groups consume fewer and/or quicker, but less healthy, meals relative to teenagers participating either in all three programs or in none of the programs. On the other hand, we obtain a positive, but statistically insignificant, coefficient on the dummy variable indicating participation in all three programs (in stark contrast to the sum of the coefficients on SMEAL and SNAP being negative and large in magnitude). For secondary eating and drinking and personal care, while some of the individual coefficients are quite sizeable, they are all measured very imprecisely. Finally, for television and movie viewing, we find a positive and statistically significant association for SNAP (84 minutes more). On the other hand, participation in all three programs (27 minutes less) is associated with less time watching television or movies. Thus, the time allocation results suggest that one mechanism by which household participation in all three programs may lead to the lower BMI found in Table 2 is through greater time allocated to primary eating and drinking and less time spent in the sedentary activity of watching television and movies.

\footnotetext{
${ }^{28}$ Following the results in Stewart (2009), we estimate time allocations using OLS instead of tobit models. We did also estimate the model by tobit with few substantitive differences. Results are available upon request.
} 
Adult Sample Next we turn to respondents 25-59 years old with at least one child between five and 18 years old or five and ten years old. Recall, our intention is not to assess the relationship between program participation and adult health per se, but rather associations with adult behavior that may shed light on the mechanisms underlying effects of program participation on child health.

Table 4 presents results analyzing several different time allocations. ${ }^{29}$ Panel A (Panel B) uses the sample of respondents with at least one child between five and 18 (ten) years old. We analyze the same time allocations as in Table 3, plus time devoted to food preparation, grocery shopping (including travel time), and caring for household children. The control set includes gender, age and age squared, race, region, education, and marital status. To begin, note that we reject the null that the five coefficients of interest are jointly equal to zero at the $p<0.10$ confidence level for primary eating and drinking, caring for children, personal care, watching television and movies, and grocery shopping in Panel A; only for grocery shopping in Panel B. In addition, we reject the null that there are no spillover effects from multiple program participation at the $p<0.10$ confidence level for primary eating and drinking in Panel A, as well as grocery shopping in Panels A and B. Specifically, we reject the null that the coefficient on ALL is equal to the sum of the coefficients on SNAP and SMEAL. While we cannot rule out the possibility that reflects selection, in our view this provides a strong warning to researchers to avoid drawing conclusions regarding participation in multiple programs from individual program effects without providing some justification.

In terms of the individual coefficient estimates, several interesting potential pathways between program participation and child health are suggested. First, all participation categories except NSLP only are associated with less time allocated to primary eating and drinking; the relationship is statistically significant for SNAP (14 minutes less). For SNAP, this reduction in time spent in primary in eating and drinking is accompanied by an increase in secondary eating (4-6 minutes) and drinking (21-33 minutes) although the point estimates are not precisely estimated. Second, nearly all participation categories are associated with less time spent grocery shopping; the relationship is statistically significant for SNAP in both Panels A and B and SMEAL in Panel A. However, when we restrict the sample to only observations with a strictly positive allocation of time spent grocery shopping, the associations are never statistically significant (although the sample size is reduced) and many of the point estimates become positive. While not overwhelming, this does suggest that food deserts may play an important role in understanding the linkages between program participation in child health. Specifically, program participants are less likely to engage in grocery shopping,

\footnotetext{
${ }^{29}$ Note, the total sample size is now 3,843 as we include an additional 50 observations that report participation in SBP only or SBP and SNAP (but not NSLP). Given the small number in each of these two treatments, however, we do not treatment dummies for these categories. The results are nearly identical - and available upon request - if we exclude these 50 observations.
} 
but spend (perhaps) more time on grocery shopping (including travel time) conditional on a non-zero time allocation.

Aside from these food related time categories, we also find several positive and statistically significant associations between program participation and child care and watching television and movies. For example, participants in all three programs spend roughly 15 minutes more watching television and movies and ten to 16 minutes more caring for children. This is most likely attributable to the increased idle time among these respondents due to lower labor force attachment (see Table 1). As indicated earlier, this finding suggests that policymakers may wish to include information on healthier options for spending one's time, such as sports and recreational exercise, in outreach efforts such as SNAP-Ed.

Table 5 is identical to Table 4 except the sample is restricted to respondents living in households with an income below $\$ 75,000$. This makes the treatment and control groups a bit more comparable. In the interest of brevity, we emphasize a few of the more significant findings. First, despite the loss in sample size, we continue to reject the null that the five coefficients of interest are jointly equal to zero at the $p<0.10$ confidence level for primary eating and drinking, caring for children, and watching television and movies in Panel A; the null continues to be rejected for grocery shopping in Panel B as well. We also reject the null that there are no spillover effects from multiple program participation at the $p<0.10$ confidence level for primary eating and drinking in Panel B. Second, many of the statistically significant associations found in Table 4 remain in Table 5. In particular,.the negative association between participation in all categories of program participation and time allocated to primary eating and drinking remains, as does the positive association with watching television and movies. The fact that association between participation in both SNAP and NSLP and primary eating and drinking is statistically significant and economically large (24-33 minutes less) is especially noteworthy. Of the changes that do arise, perhaps the most relevant is that we observe a weaker positive association between different categories of program participation and time allocated to child care. In fact, in Panel B we find that SNAP participation is associated with a statistically significant reduction in time devoted to child care (16 minutes less). Again, this suggests some scope for bundling nutrition education under SNAP-Ed with general information on parenting skills.

In sum, the multivariate analysis reinforces the suggestive evidence from the descriptive analysis: the association between program participation and time allocation is not additive. While future research is needed to discover if this simply reflects differential selection into multiple programs versus single programs or actual spillovers from joint program participation, in the mean time researchers should be cautious when examining programs in isolation and policymakers should not view programs as simple substitutes. Moreover, the analysis here reveals strong evidence suggesting a causal beneficial effect of simultaneous participation in all three nutrition programs on adolescent BMI. The evidence suggests that one mechanism 
by which this occurs is through a greater time allocation of adolescents in these households to primary eating and drinking and adults in these households to child care.

\section{Conclusion}

Using the latest 2007 ATUS data along with the Eating and Health Module, our analysis reveals several salient behavioral differences in terms of time allocation across households that participate in different combinations of the three largest federal nutrition programs: the School Breakfast Program, the National School Lunch Program, and the Supplemental Nutrition Assistance Program. Such differences are important for several reasons. First, they shed some light on the possible mechanisms by which participation in different combinations of these programs may ultimately impact childhood obesity. Second, it is currently a pivotal time for each of these three programs; understanding the behaviors of those participating is vital as policymakers move forward. President Obama's task force on childhood obesity sent a report to the president in May 2010 that unveiled a 70-point plan to combat childhood obesity. ${ }^{30}$ Components of this plan include: (i) increase participation in SNAP by eligible households to $75 \%$, increase participation in NSLP by two million children, and increase participation in SBP by three million students, (ii) revise the USDA's and Health and Human Service's (HHS) 2010 Dietary Guidelines for Americans and SNAP-Ed program to help convey useful and easy to understand information regarding a health lifestyle, and (iii) launch a multi-year, multi-agency initiative to improve access to healthy food in underserved urban and rural areas.

In terms of outreach efforts like SNAP-Ed, the analysis here suggests that revisions ought to do more than focus solely on dietary guidelines. Adults residing in households with income less than $\$ 75,000$ participating in SNAP tend to spend less time in primary eating and drinking, more time watching television and movies, less time caring for children, and less time grocery shopping. In addition, participating households in any program (or programs) except NSLP only tend to have lower labor force attachment, less income, be in worse overall health, be non-white, be single-parent households, allocate less time to child health, and spend longer grocery shopping conditional on allocating any time at all. Households participating only in NSLP are the most advantaged economically on average. Thus, when establishing guidelines for achieving and maintaining a healthy lifestyle for children in these participating households, recognizing who the target audience is may increase the efficacy of the message.

The other main conclusion from our analysis concerns the likely presence of spillovers from participating in multiple programs. Throughout the analysis, we found many cases where the relationship between

\footnotetext{
${ }^{30}$ See http://www.letsmove.gov/tfco_fullreport_may2010.pdf.
} 
participation in all three programs and outcomes of interest differed (in an economic and statistical sense) from that which one would infer from "summing" the relationships from participating in each of the programs in isolation. While it is possible that this is driven entirely by nonrandom selection in multiple programs, researchers should model combinations of program participation as unique treatments in the absence of solid evidence to that effect. In the current analysis, this fact was particularly striking when analyzing the association between program participation and BMI of adolescents. While the estimated associations with NSLP, SBP and NSLP, and SNAP are all found to be positive, the association with participation in all three programs is negative and quite meaningful. Given the expected direction of any bias due to nonrandom selection, this association likely represents a causal relationship. Further analysis on time allocation suggests that the underlying mechanism behind this likely positive causal effect of joint participation on BMI pertains to greater time devoted to child care by parents, as well as less time spent by adolescents watching television and movies. 


\section{References}

[1] Aguiar, M. and E. Hurst (2007), "Measuring Trends in Leisure: The Allocation of Time over Five Decades," Quarterly Journal of Economics, 122, 969-1006.

[2] Alaimo, K. , C. Olson, and E. Frongillo (2001), "Low Family Income and Food Insufficiency in Relation to Overweight in US Children," Archives of Pediatric and Adolescent Medicine, 155, 1161-1167.

[3] Anderson, P.M. (2010), "Parental Employment, Family Routines and Childhood Obesity," Dartmouth College, unpublished manuscript.

[4] Anderson, P.M., K.F. Butcher, and P.B. Levine (2003), "Maternal Employment and Overweight Children," Journal of Health Economics, 22, 477-504.

[5] Baum, C.L. and C.J. Ruhm (2007), "Age, Socioeconomic Status, and Obesity Growth,” NBER Working Paper No. 13289.

[6] Betrand, M. and D. Whitmore Schanzenbach (2009), "Time Use and Food Consumption," American Economic Review, 99, 170-176

[7] Besharov, D. (2002), "We Are Feeding the Poor As If They're Starving," Washington Post, December 8.

[8] Besharov, D. (2003), "Growing Overweight and Obesity in America: The Potential Role of Federal Nutrition Programs," Testimony Prepared for the Committee on Agriculture, Nutrition, and Forestry, U.S. Senate, April.

[9] Bhattacharya, J., J. Currie, and S. Haider (2006), "Breakfast of Champions? The School Breakfast Program and the Nutrition of Children and Families," Journal of Human Resources, 41, 445-466.

[10] Bitler, M. and S.J. Haider (2010), “An Economic View of Food Deserts in the United States," Journal of Policy Analysis and Management, forthcoming.

[11] Brown, J.E., D.H. Broom, J.M. Nicholson, and M. Bittman (2010), "Do Working Mothers Raise Couch Potato Kids? Maternal Employment and Children's Lifestyle Behaviours and Weight in Early Childhood," Social Science and Medicine, forthcoming.

[12] Burghardt, J.A., A.R. Gordon and T.M. Fraker (1995), "Meals Offered in the National School Lunch Program and the School Breakfast Program," American Journal of Clinical Nutrition, 61 (Supplement), 187S-198S. 
[13] Cardosa, A.R., E. Fontainha, and C. Monfardini (2010), "Children's and Parents' Time Use: Empirical Evidence on Investment in Human Capital in France, Germany, and Italy," Review of Economics of the Household, 8, 479-504.

[14] Cawley, J. (2010), "The Economics of Childhood Obesity," Health Affairs, 29, 364-371.

[15] Cawley, J. and F. Liu (2007), "Maternal Employment and Childhood Obesity: A Search for Mechanisms in Time Use Data," NBER Working Paper No. 13600.

[16] Cawley, J. , C. Meyerhoefer, and D. Newhouse (2005), "The Impact Of State Physical Education Requirements on Youth Physical Activity and Overweight," NBER Working Paper No. 11411.

[17] Chen, Z., S.T. Yen, and D.B. Eastwood (2005), "Effects Of Food Stamp Participation on Body Weight and Obesity," American Journal of Agricultural Economics, 87, 1167-1173.

[18] Cole, N. and M.K. Fox (2008), "Diet Quality of Americans by Food Stamp Participation Status: Data from the National Health and Nutrition Examination Survey, 1999-2004," USDA, Food and Nutrition Service, Report No. FSP-08-NH.

[19] Cooper, R. and M. Levin (2006), School Breakfast Scorecard 2006, Food Research and Action Center, Washington, D.C.

[20] Dunifon, R. and L. Kowaleski-Jones (2003), "The Influences of Participation in the National School Lunch Program and Food Insecurity on Child Well-Being," Social Service Review, 77, 72-92.

[21] Ebbling, C.B. , D.B. Pawlak, and D.S. Ludwig. (2002), "Childhood Obesity: Public-Health Crisis,Common Sense Cure," The Lancet, 360, 473-482.

[22] Elkins, W.L. , D.A. Cohen, L.M. Koralewicz, and S. Taylor (2004), "After School Activities, Overweight, and Obesity Among Inner City Youth," Journal of Adolescence, 27, 181-189

[23] Fertig, A. , G. Glomm, and R. Tchernis (2009), "The Connection Between Maternal Employment and Childhood Obesity: Inspecting the Mechanisms," Review of Economics of the Household, 7, 227-255.

[24] Finkelstein, E. A. , I.C. Fiebelkorn, and G. Wang (2004), "State-Level Estimates of Annual Medical Expenditures Attributable to Obesity," Obesity Research, 12.

[25] Flegal, K.M. , B.I. Graubard, D.F. Williamson, and M.H. Gail (2005), "Excess Deaths Associated With Underweight, Overweight and Obesity," Journal of the American Medical Association, 293, $1861-1867$. 
[26] Fox, M.K., W. Hamilton, and B. Lin (2004), "Effects of Food Assistance and Nutrition Programs on Nutrition and Health: Volume 4, Executive Summary of the Literature Review," Food Assistance and Nutrition Research Report Number 19-4.

[27] Gibson, D. (2003), "Food Stamp Program Participation is Positively Related to Obesity in Low Income Women," Journal of Nutrition, 133, 2225-2231.

[28] Gleason, P.M. (1995), "Participation in the National School Lunch Program and the School Breakfast Program," American Journal of Clinical Nutrition, 61 (Supplement), 213S-220S.

[29] Gleason, P.M. and C.W. Suitor (2003), "Eating at School: How the National School Lunch Program Affects Children's Diets," American Journal of Agricultural Economics, 85, 1047-1061.

[30] Gordon, A.R., B.L. Devaney, and J.A. Burghardt (1995), "Dietary Effects of the National School Lunch Program and the School Breakfast Program," American Journal of Clinical Nutrition, 61 (Supplement), 221S-231S.

[31] Guthrie, J.F., E. Frazao, M. Andrews, and D. Smallwood (2007), "Improving Food Choices - Can Food Stamps do More?," Amber Waves, 5, Feature.

[32] Hamermesh, D.S. (2009), "Grazing, Goods and Girth:Determinants and Effects," IZA Discussion Paper No. 4378

[33] Hinrichs, P. (2010), "The Effects of the National School Lunch Program on Education and Health," Journal of Policy Analysis and Management, forthcoming.

[34] Hofferth, S.L. and S. Curtin (2005), "Poverty, Food Programs, and Childhood Obesity," Journal of Policy Analysis and Management, 24, 703-726.

[35] Hoynes, H.W. and D.W. Schanzenbach (2009), "Consumption Responses to In-Kind Transfers: Evidence from the Introduction of the Food Stamp Program," American Economic Journal: Applied Economics, 1, 109-139.

[36] Jones, S.J., L. Jahns, B.A. Laraia, and B. Haughton (2003), "Lower Risk of Overweight in Schoolaged Food Insecure Girls Who Participate in Food Assistance," Archives of Pediatric and Adolescent Medicine, 157, 780-784.

[37] Juster, F.T. and F.P. Stafford (1991), "The Allocation of Time: Empirical Findings, Behavioral Models, and Problems of Measurement," Journal of Economic Literature, 29, 471-522 
[38] Kalenkoski, C.M. and L.S. Stratton (2008), "Adult Eating Behaviors and Weight Status: A Time Use Analysis," unpublished manuscript.

[39] Kaushal, N. (2007), "Do Food Stamps Cause Obesity? Evidence From Immigrant Experience," Journal of Health Economics, 26, 968-991.

[40] Kimm, S., E. Obarzanek, B. Barton, C. Aston, S. Similo, J. Morrison, Z.I. Sabry, G.B. Schreiber, and R.P. McMahon (1996), "Race, Socioeconomic Status, and Obesity in 9- to 10-year-old Girls: The NHLBI Growth and Health Study," Academy of Epidemiology and Pediatrics, 6, 266-275.

[41] Kreider, B., J. Pepper, C. Gundersen, and D. Jolliffe (2009), "Identifying the Effects of Food Stamps on Child Health Outcomes When Participation is Endogenous and Misreported," unpublished manuscript, Iowa State University.

[42] Liu, G. C., J.S. Wilson, R. Qi, and J. Ying (2006), "Green Neighborhoods, Food Retail and Childhood Overweight: Differences by Population Density," American Journal of Health Promotion, Inc., August 21.

[43] Long, S.K. (1991), "Do School Nutrition Programs Supplement Household Food Expenditures?” Journal of Human Resources, 26, 654-678.

[44] Meyerhoefer, C.D. and Y. Pylypchuk (2008), "Does Participation in the Food Stamp Program Increase the Prevalence of Obesity and Health Care Spending?" American Journal of Agricultural Economics, 90, 287-305

[45] Millimet, D.L., M. Husain, and R. Tchernis (2010), "School Nutrition Programs and the Incidence of Childhood Obesity," Journal of Human Resources, 45, 640-654.

[46] Mokdad, A.H., J.S. Marks, D.F. Stroup, and J.L. Gerberding (2004), "Actual Causes of Death in the United States (2000)," Journal of the American Medical Association, 291(10), 1238-1245.

[47] Mullahy, J. and S.A. Robert (2010), "No Time to Lose: Time Constraints and Physical Activity in the Production of Health," Review of Economics of the Household, 8, 409-432.

[48] Newman, C., A. Clauson, and K. Ralston (2008), "Balancing Nutrition, Participation, and Cost in the National School Lunch Program," Amber Waves, 6, Feature.

[49] Rashad, I. and M. Grossman (2004), "The Economics of Obesity," The Public Interest,Research Report, Summer. 
[50] Rosin, O. (2008), "The Economic Causes of Obesity: A Survey," Journal of Economic Surveys, 22, 617-647.

[51] Schanzenbach, D.W. (2009), "Do School Lunches Contribute to Childhood Obesity?" Journal of Human Resources, 44, 684-709.

[52] Serdula, M.K., D. Ivery, R.J. Coates, D.S. Freedman, D.F. Williamson, and T. Byers (1993), "Do Obese Children Become Obese Adults? A Review of the Literature," Preventative Medicine, 22, 167-177.

[53] Shahar, D., I. Shai, H. Vardi, A. Shahar, and D. Fraser (2005), "Diet and Eating Habits in High and Low Socioeconomic Groups," Nutrition, 21, 559-566

[54] Shiv, B. and A. Fedorikhin (1999), "Heart and Mind in Conflict: The Interplay of Affect and Cognition in Consumer Decision Making," Journal of Consumer Research, 26, 278-292.

[55] Stallings, V.A. and C.L. Taylor, eds. (2008), Nutrition Standards and Meal Requirements for National School Lunch and Breakfast Programs: Phase I. Proposed Approach for Recommending Revisions, The National Academies Press: Washington, D.C.

[56] Stewart, J. (2009), “Tobit of Not Tobit?” IZA Discussion Paper No. 4588.

[57] Townsend, M., J. Peerson, B. Love, C. Achterberg, and S. Murphy (2001), "Food Insecurity Is Positively Related to Overweight in Women," Journal of Nutrition, 131, 1738-1745.

[58] U.S. White House Task Force on Childhood Obesity (2010), Solving the Problem of Childhood Obesity Within a Generation, Report to the President, May.

[59] Ver Ploeg, M., L. Mancino, and B. Lin (2006), "Food Stamps and Obesity: Ironic Twist or Complex Puzzle?" Amber Waves, 4, February.

[60] von Hippel, P.T., B. Powell, D.B. Downey, and N.J. Rowland (2007), "The Effect of School on Overweight in Childhood: Gain in Body Mass Index During the School Year and During Summer Vacation," American Journal of Public Health, 97, 696-70

[61] Wang, Y. and M.A. Beydoun (2007), "The Obesity Epidemic in the United States - Gender, Age, Socioeconomic, Racial/Ethnic, and Geographic Characteristics: A Systematic Review and MetaRegression Analysis," Epidemiologic Reviews, 29, 6-28.

[62] Wansink, B. (2006), Mindless Eating: Why We Eat More than We Think, New York: Bantam Books. 
[63] Whitmore, D. (2002), "What Are Food Stamps Worth?" Working Paper \#468, Industrial Relations Section, Princeton University.

[64] Wilde, P. E. and M.S. Andrews (2000), "The Food Stamp Program in an Era of Welfare Reform: Electronic Benefits and Changing Sources of Cash Income," Journal of Consumer Affairs, 34, 31-46.

[65] World Health Organization (1998), "Obesity: Preventing and Managing the Global Epidemic," WHO Technical Report 894. 


\begin{tabular}{|c|c|c|c|c|c|c|c|c|c|c|c|c|}
\hline \multirow[b]{2}{*}{ Variable } & \multicolumn{2}{|c|}{ Only NSLP } & \multicolumn{2}{|c|}{ Only SBP \& NSLP } & \multicolumn{2}{|c|}{ Only SNAP } & \multicolumn{2}{|c|}{ Only SNAP \& NSLP } & \multicolumn{2}{|c|}{ All Programs } & \multicolumn{2}{|c|}{ Participation in None } \\
\hline & Mean & SD & Mean & SD & Mean & SD & Mean & SD & Mean & SD & Mean & SD \\
\hline \multicolumn{13}{|l|}{ Time Allocation } \\
\hline Total Time Spent In Primary Eating and Drinking & 67.045 & 46.636 & $58.592 * * *$ & 41.731 & $45.079 * * *$ & 36.368 & $45.006 * * *$ & 46.062 & $50.597 * * *$ & 39.447 & 64.706 & 44.245 \\
\hline Total Time Spent In Secondary Eating & 24.918 & 99.121 & 23.541 & 85.707 & 32.418 & 126.396 & $18.844 * * *$ & 33.774 & 21.558 & 82.663 & 25.704 & 110.033 \\
\hline Total Time Spent In Secondary Drinking & $76.265^{*}$ & 197.897 & 58.277 & 169.345 & 94.713 & 246.122 & 59.346 & 178.195 & $64.131 *$ & 203.140 & 66.222 & 188.213 \\
\hline Grocery Shopping & 5.049 & 15.294 & $3.987 * * *$ & 13.916 & 2.574 & 11.949 & 4.392 & 16.903 & 5.562 & 16.145 & 5.974 & 17.122 \\
\hline Travel Time Related to Grocery Shopping & 2.653 & 8.323 & $1.660 * * *$ & 6.137 & 2.122 & 7.896 & 1.480 & 6.029 & 2.914 & 10.315 & 3.370 & 10.317 \\
\hline Purchasing Food (Not Groceries) & 1.473 & 5.247 & 1.357 & 3.883 & 1.249 & 4.892 & 2.426 & 5.474 & $0.570 * * *$ & 2.730 & 1.555 & 5.026 \\
\hline $\begin{array}{l}\text { Consumer Purchases Except Food } \\
\text { and Grocery Shopping }\end{array}$ & $11.691 *$ & 28.437 & 9.339 & 24.195 & 11.156 & 30.515 & 6.318 & 15.128 & $5.606 * * *$ & 19.075 & 11.093 & 25.860 \\
\hline Food Preparation & 34.663 & 44.001 & $34.096^{*}$ & 45.970 & 33.455 & 41.679 & $52.165 * * *$ & 60.139 & 38.222 & 44.037 & 35.876 & 46.352 \\
\hline Personal Care & 61.087 & 49.767 & $61.700 * *$ & 47.924 & $50.004 *$ & 43.754 & 58.840 & 59.497 & 49.681 & 50.331 & 57.101 & 48.340 \\
\hline Caring For and Helping Household Children & $41.182 * * *$ & 61.352 & $41.998 * *$ & 57.167 & 33.472 & 51.297 & 36.263 & 58.150 & $47.067 * * *$ & 59.149 & 32.056 & 58.316 \\
\hline Activities Related To Household Children's Education & $6.007 * * *$ & 17.793 & $6.077 * * *$ & 18.021 & 3.267 & 19.725 & 6.803 & 18.798 & $10.213 * * *$ & 23.620 & 2.850 & 13.085 \\
\hline Activities Related To Household Children's Health & 0.629 & 5.302 & 1.251 & 9.365 & $0.032 * * *$ & 0.620 & $0.000 * * *$ & 0.000 & 0.605 & 4.729 & 0.717 & 7.187 \\
\hline Activities Related To Household Adults & 0.686 & 5.542 & 0.640 & 4.366 & $0.256^{* * *}$ & 1.509 & $0.151 * * *$ & 1.292 & 0.785 & 3.094 & 0.680 & 4.446 \\
\hline Caring For and Helping Non-Household Members & 1.663 & 9.900 & 1.690 & 9.677 & 3.964 & 22.395 & 4.705 & 17.126 & 2.553 & 16.402 & 1.957 & 10.341 \\
\hline Work and Work-Related Activities & 18.181 & 44.438 & $20.330^{*}$ & 43.259 & $8.653 * *$ & 26.632 & $41.304 *$ & 61.329 & $8.300 * * *$ & 25.466 & 15.999 & 40.622 \\
\hline Participating in Sports, Exercise, or Recreation & 7.081 & 21.383 & $4.269 * * *$ & 16.718 & $1.729 * * *$ & 8.234 & $1.736 * * *$ & 7.976 & $6.034 * * *$ & 24.648 & 7.874 & 22.836 \\
\hline Sports, Exercise, and Recreation Except For Participation & 0.660 & 7.039 & 0.182 & 3.863 & $0.000 * * *$ & 0.000 & $0.000 * * *$ & 0.000 & $0.000 * * *$ & 0.000 & 0.208 & 3.840 \\
\hline Television and Movies (Not Religious and Religious) & $47.829 * * *$ & 53.061 & $49.607 * *$ & 60.141 & $52.260^{*}$ & 54.710 & 51.069 & 55.710 & $57.574^{*}$ & 62.377 & 42.315 & 51.715 \\
\hline Relaxing and Leisure & 69.222 & 64.721 & 68.188 & 74.324 & 67.833 & 70.686 & 89.611 & 82.147 & 72.022 & 78.397 & 70.096 & 68.904 \\
\hline Socializing, Relaxing, and Leisure & $16.669 * * *$ & 31.205 & 16.980 & 34.362 & 14.952 & 33.729 & $18.761 * * *$ & 30.742 & $14.281 * * *$ & 32.716 & 18.999 & 35.593 \\
\hline \multicolumn{13}{|l|}{ Except Explicitly Relaxing/Leisure } \\
\hline \multicolumn{13}{|l|}{ Health Variables } \\
\hline Height (in.) & 67.108 & 4.014 & 66.411 & 4.241 & 66.596 & 4.537 & $65.341 * *$ & 4.760 & $65.809 * * *$ & 3.748 & 66.942 & 3.987 \\
\hline Weight (lbs.) & 176.599 & 42.136 & $181.219^{* * *}$ & $* 41.422$ & 191.107 & 49.904 & $185.634^{*}$ & 44.750 & 179.374 & 45.051 & 174.931 & 41.175 \\
\hline BMI & 27.330 & 5.269 & $28.896 * * *$ & 6.136 & $30.232 * * *$ & 6.947 & $30.678 * * *$ & 6.660 & $29.302 * * *$ & 7.218 & 27.278 & 5.460 \\
\hline Obese $(\mathrm{BMI}>30)$ & $0.258^{*}$ & 0.438 & $0.318 * * *$ & 0.466 & $0.418^{* * *}$ & 0.497 & $0.443 * * *$ & 0.501 & $0.343 * * *$ & 0.476 & 0.225 & 0.418 \\
\hline Overweight $(\mathrm{BMI}>25)$ & 0.337 & 0.473 & 0.349 & 0.477 & 0.383 & 0.489 & 0.344 & 0.479 & $0.289 * * *$ & 0.455 & 0.346 & 0.476 \\
\hline Health $($ Poor $=1)$ & 0.017 & 0.129 & $0.027^{*}$ & 0.162 & $0.131 * * *$ & 0.339 & 0.140 & 0.350 & $0.117 * * *$ & 0.323 & 0.014 & 0.119 \\
\hline Health $($ Fair $=1)$ & 0.075 & 0.264 & $0.132 * * *$ & 0.339 & $0.145^{* * *}$ & 0.354 & $0.213^{* * *}$ & 0.413 & $0.147 * * *$ & 0.355 & 0.065 & 0.247 \\
\hline Health $($ Good $=1)$ & $0.292 * *$ & 0.455 & $0.385^{* * *}$ & 0.487 & 0.323 & 0.471 & $0.387 * * *$ & 0.491 & $0.438 * * *$ & 0.498 & 0.267 & 0.442 \\
\hline Health $($ Very Good $=1)$ & 0.412 & 0.492 & $0.318^{* *}$ & 0.466 & $0.191 * * *$ & 0.396 & $0.128 * * *$ & 0.337 & $0.186^{* * *}$ & 0.390 & 0.375 & 0.484 \\
\hline Health $($ Excellent $=1)$ & $0.202 * *$ & 0.402 & $0.138 * * *$ & 0.345 & 0.210 & 0.410 & $0.132 * * *$ & 0.342 & $0.111 * * *$ & 0.315 & 0.243 & 0.429 \\
\hline
\end{tabular}




\begin{tabular}{|c|c|c|c|c|c|c|c|c|c|c|c|c|}
\hline \multirow[b]{2}{*}{ Variable } & \multicolumn{2}{|c|}{ Only NSLP } & \multicolumn{2}{|c|}{ Only SBP \& NSLP } & \multicolumn{2}{|c|}{ Only SNAP } & \multicolumn{2}{|c|}{ Only SNAP \& NSLP } & \multicolumn{2}{|c|}{ All Programs } & \multicolumn{2}{|c|}{ Participation in None } \\
\hline & Mean & SD & Mean & SD & Mean & SD & Mean & SD & Mean & SD & Mean & SD \\
\hline \multicolumn{13}{|l|}{ Economic Characteristics } \\
\hline Part-Time Job & 0.129 & 0.335 & $0.096^{* * *}$ & 0.295 & 0.234 & 0.426 & 0.290 & 0.458 & 0.129 & 0.336 & 0.145 & 0.352 \\
\hline Full-Time Job & 0.701 & 0.458 & $0.758 * * *$ & 0.428 & $0.359 * * *$ & 0.483 & $0.335^{* * *}$ & 0.476 & $0.444 * * *$ & 0.498 & 0.659 & 0.474 \\
\hline Not in Labor Force & 0.142 & 0.349 & $0.125 * * *$ & 0.330 & $0.292 * * *$ & 0.458 & $0.285 * * *$ & 0.456 & $0.348 * * *$ & 0.478 & 0.159 & 0.366 \\
\hline Unemployed - Looking & 0.018 & 0.135 & 0.019 & 0.138 & $0.114 * * *$ & 0.320 & $0.079 *$ & 0.272 & $0.079 * * *$ & 0.271 & 0.033 & 0.179 \\
\hline Total Hours Worked Per Week & 42.397 & 12.196 & 42.722 & 12.052 & $34.051 * * *$ & 8.833 & 37.300 & 10.957 & $38.822 * * *$ & 10.278 & 41.461 & 13.236 \\
\hline Spouse/Unmarried Partner Not Employed & $0.154 * *$ & 0.361 & $0.125 * * *$ & 0.331 & 0.287 & 0.456 & 0.194 & 0.399 & 0.300 & 0.459 & 0.171 & 0.377 \\
\hline Spouse/Unmarried Partner Employed & $0.727 * * *$ & 0.445 & 0.688 & 0.464 & $0.349 * * *$ & 0.480 & $0.259 * * *$ & 0.442 & $0.206^{* * *}$ & 0.406 & 0.696 & 0.460 \\
\hline Usual Hours Of Work Of Spouse/Unmarried Partner & 42.124 & 13.073 & 42.042 & 11.917 & $33.342 * * *$ & 12.279 & 43.117 & 11.361 & 38.564 & 15.736 & 41.601 & 12.420 \\
\hline Income $<\$ 15,000$ & 0.022 & 0.147 & $0.068 * * *$ & 0.252 & $0.380 * * *$ & 0.489 & $0.312 * * *$ & 0.468 & $0.526 * * *$ & 0.501 & 0.032 & 0.175 \\
\hline Income $\$ 15,000-\$ 40,000$ & 0.166 & 0.372 & $0.300 * * *$ & 0.459 & $0.352 * * *$ & 0.481 & $0.304 * * *$ & 0.464 & $0.296 * * *$ & 0.458 & 0.142 & 0.350 \\
\hline Income $\$ 40,000$ - $\$ 75,000$ & 0.267 & 0.443 & 0.292 & 0.455 & $0.201 * * *$ & 0.403 & $0.219 * * *$ & 0.417 & $0.081 * * *$ & 0.273 & 0.294 & 0.456 \\
\hline Income $\$ 75,000-\$ 150,000$ & 0.316 & 0.465 & $0.197 * * *$ & 0.398 & $0.027 * * *$ & 0.164 & $0.017 * * *$ & 0.132 & $0.000 * * *$ & 0.000 & 0.299 & 0.458 \\
\hline Income $>\$ 150,000$ & $0.114 * *$ & 0.318 & $0.035 * * *$ & 0.184 & $0.005 * * *$ & 0.070 & $0.000 * * *$ & 0.000 & $0.000 * * *$ & 0.000 & 0.097 & 0.296 \\
\hline \multicolumn{13}{|l|}{ Demographic Characteristics } \\
\hline Age & $41.385 * * *$ & 7.162 & $38.637 * * *$ & 7.725 & $36.497 * * *$ & 6.992 & $36.658 * * *$ & 7.709 & $35.876 * * *$ & 8.195 & 42.135 & 7.880 \\
\hline Male & 0.473 & 0.499 & 0.467 & 0.499 & $0.308 * * *$ & 0.465 & $0.341 * * *$ & 0.478 & $0.362 * * *$ & 0.482 & 0.444 & 0.497 \\
\hline White, Non-Hispanic & $0.725^{*}$ & 0.447 & $0.488 * * *$ & 0.500 & $0.405 * * *$ & 0.494 & $0.242 * * *$ & 0.432 & $0.281 * * *$ & 0.451 & 0.690 & 0.463 \\
\hline White, Hispanic & 0.150 & 0.358 & $0.286^{* * *}$ & 0.452 & $0.228 *$ & 0.422 & $0.389 * * *$ & 0.492 & $0.246^{* * *}$ & 0.432 & 0.158 & 0.365 \\
\hline Non-White, Hispanic & $0.006^{* *}$ & 0.080 & $0.008 * * *$ & 0.092 & 0.012 & 0.111 & 0.068 & 0.253 & $0.039 * * *$ & 0.195 & 0.002 & 0.048 \\
\hline Black & 0.060 & 0.238 & $0.184 * * *$ & 0.388 & $0.281 * * *$ & 0.453 & $0.264 * * *$ & 0.445 & $0.407 * * *$ & 0.493 & 0.088 & 0.283 \\
\hline Asian & $0.039 *$ & 0.194 & $0.015^{* * *}$ & 0.121 & 0.019 & 0.137 & $0.011 *$ & 0.104 & $0.006 * * *$ & 0.077 & 0.045 & 0.207 \\
\hline Native & 0.798 & 0.402 & $0.723 * * *$ & 0.448 & 0.747 & 0.438 & 0.788 & 0.413 & 0.763 & 0.426 & 0.808 & 0.395 \\
\hline Citizen By Naturalization & 0.072 & 0.259 & $0.082 *$ & 0.275 & 0.067 & 0.252 & 0.033 & 0.181 & $0.024^{*}$ & 0.155 & 0.059 & 0.236 \\
\hline Foreign, Not US Citizen & 0.105 & 0.307 & $0.180 *$ & 0.384 & 0.163 & 0.372 & 0.120 & 0.328 & 0.169 & 0.376 & 0.119 & 0.324 \\
\hline Married and Spouse Present & $0.843 * *$ & 0.364 & $0.756^{* * *}$ & 0.430 & $0.539 * * *$ & 0.502 & $0.400 * * *$ & 0.494 & $0.435 * * *$ & 0.497 & 0.828 & 0.377 \\
\hline Married and Spouse Present or Absent & $0.844 * *$ & 0.363 & $0.758 * * *$ & 0.428 & $0.539 * * *$ & 0.502 & $0.400 * * *$ & 0.494 & $0.435 * * *$ & 0.497 & 0.830 & 0.376 \\
\hline High School Graduate & 0.288 & 0.453 & $0.358 * * *$ & 0.480 & 0.261 & 0.442 & 0.220 & 0.418 & $0.508 * * *$ & 0.501 & 0.260 & 0.439 \\
\hline Some College & 0.162 & 0.368 & 0.165 & 0.371 & $0.298 * * *$ & 0.460 & 0.234 & 0.427 & 0.103 & 0.305 & 0.152 & 0.359 \\
\hline Associate Degree & 0.123 & 0.328 & 0.098 & 0.298 & $0.033 * *$ & 0.181 & 0.084 & 0.279 & 0.071 & 0.258 & 0.116 & 0.320 \\
\hline Bachelor's Degree & 0.234 & 0.423 & $0.161 * * *$ & 0.368 & $0.108 * * *$ & 0.313 & $0.038 * * *$ & 0.193 & $0.015 * * *$ & 0.123 & 0.239 & 0.426 \\
\hline Master's Degree & 0.083 & 0.275 & $0.040 * * *$ & 0.196 & $0.007 * * *$ & 0.086 & $0.024 * * *$ & 0.154 & $0.000 * * *$ & 0.000 & 0.093 & 0.291 \\
\hline Higher Than Master's Degree & $0.027 * * *$ & 0.163 & $0.005 * * *$ & 0.068 & $0.000 * * *$ & 0.000 & $0.000 * * *$ & 0.000 & $0.000 * * *$ & 0.000 & 0.035 & 0.185 \\
\hline Northeast & 0.201 & 0.401 & $0.132 * * *$ & 0.339 & $0.099 *$ & 0.300 & 0.207 & 0.409 & $0.119^{*}$ & 0.325 & 0.189 & 0.391 \\
\hline Midwest & $0.265 * * *$ & 0.442 & 0.214 & 0.410 & 0.202 & 0.404 & 0.174 & 0.383 & 0.177 & 0.383 & 0.245 & 0.430 \\
\hline South & 0.309 & 0.462 & $0.427 * * *$ & 0.495 & 0.498 & 0.503 & 0.330 & 0.474 & $0.581 * * *$ & 0.495 & 0.328 & 0.470 \\
\hline West & $0.225^{*}$ & 0.418 & $0.227 * * *$ & 0.419 & 0.201 & 0.403 & 0.288 & 0.457 & $0.123 * * *$ & 0.329 & 0.238 & 0.426 \\
\hline Metropolitan & $0.845^{*}$ & 0.362 & $0.760 * * *$ & 0.428 & 0.834 & 0.378 & 0.873 & 0.336 & $0.715 * * *$ & 0.453 & 0.860 & 0.347 \\
\hline Number Of Household Children $<18$ & $1.959 * * *$ & 0.991 & $2.203 * * *$ & 1.024 & $2.429 * * *$ & 1.163 & $2.897 * * *$ & 1.744 & $2.725 * * *$ & 1.429 & 1.768 & 1.104 \\
\hline Number Of People Living In Respondent's Household & $4.261 * *$ & 1.124 & $4.425^{*}$ & 1.305 & 4.536 & 1.468 & 5.762 & 3.021 & $4.778 * *$ & 1.604 & 4.186 & 1.251 \\
\hline Age Of Youngest Household Child $<18$ & $8.634 * * *$ & 4.693 & $7.045^{* * *}$ & 4.675 & $5.788 * * *$ & 5.555 & $6.301 * *$ & 5.525 & $5.295 * * *$ & 4.436 & 9.364 & 5.268 \\
\hline Total Number Of Household Members In the Household & $4.244^{*}$ & 1.121 & 4.391 & 1.248 & 4.576 & 1.637 & 5.456 & 2.514 & 4.660 & 1.575 & 4.186 & 1.223 \\
\hline
\end{tabular}

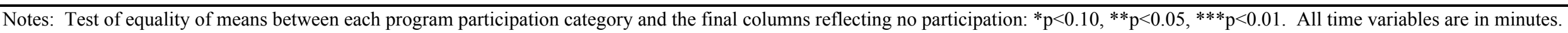

Survey weights are utilized. Number of observations = 1406 (None), 1399 (NLSP only), 686 (NSLP \& SBP only), 75 (SNAP only), 57 (SNAP \& NSLP only), and 170 (ALL) 


\begin{tabular}{|c|c|c|c|c|c|c|}
\hline & \multicolumn{3}{|c|}{$\ln (\mathrm{BMI})$} & \multicolumn{3}{|c|}{ BMI Percentile } \\
\hline & $\mathbf{I}$ & II & III & I & II & III \\
\hline \multirow[t]{2}{*}{ NSLP } & 0.010 & 0.010 & 0.012 & 1.464 & 0.645 & 0.634 \\
\hline & $(0.022)$ & $(0.022)$ & $(0.022)$ & (3.492) & $(3.211)$ & $(3.211)$ \\
\hline \multirow[t]{2}{*}{ SMEAL } & 0.039 & 0.023 & 0.018 & 4.489 & 2.366 & 0.866 \\
\hline & $(0.028)$ & $(0.027)$ & $(0.027)$ & (4.168) & (3.992) & $(4.037)$ \\
\hline \multirow[t]{2}{*}{ SNAP } & 0.099 & 0.078 & 0.074 & 12.343 & 10.368 & 9.356 \\
\hline & $(0.082)$ & $(0.083)$ & (0.094) & $(9.405)$ & $(8.447)$ & (9.931) \\
\hline \multirow[t]{2}{*}{ ALL } & -0.085 & $-0.109^{*}$ & $-0.126^{*}$ & -14.855 & -17.817 & -18.080 \\
\hline & $(0.056)$ & $(0.066)$ & $(0.069)$ & (13.180) & (13.634) & (13.130) \\
\hline \multirow[t]{2}{*}{ Male } & & -0.000 & 0.003 & & 0.943 & 1.835 \\
\hline & & $(0.019)$ & (0.019) & & $(2.561)$ & (2.605) \\
\hline \multirow[t]{2}{*}{ Age } & & 0.452 & 0.408 & & $99.779 *$ & $92.530^{*}$ \\
\hline & & $(0.375)$ & $(0.367)$ & & $(52.104)$ & (51.190) \\
\hline \multirow[t]{2}{*}{ Age Squared } & & -1.350 & -1.223 & & $-319.904 * *$ & $-298.000^{*}$ \\
\hline & & (1.158) & (1.131) & & $(160.675)$ & $(157.600)$ \\
\hline \multirow[t]{2}{*}{ Number of Household Members } & & 0.001 & 0.010 & & 0.084 & 0.527 \\
\hline & & $(0.009)$ & $(0.010)$ & & $(1.201)$ & $(1.346)$ \\
\hline \multirow[t]{2}{*}{ White } & & $-0.037^{*}$ & -0.022 & & $-5.397^{*}$ & -3.835 \\
\hline & & $(0.020)$ & $(0.020)$ & & $(2.921)$ & $(2.880)$ \\
\hline \multirow[t]{2}{*}{ Family Income $\geq \$ 50,000$} & & -0.026 & -0.017 & & -1.975 & -0.851 \\
\hline & & $(0.020)$ & $(0.020)$ & & $(2.834)$ & $(2.980)$ \\
\hline \multirow[t]{2}{*}{ Metro } & & -0.012 & -0.011 & & -0.767 & -0.209 \\
\hline & & $(0.026)$ & $(0.026)$ & & $(3.366)$ & $(3.410)$ \\
\hline \multirow[t]{2}{*}{ Northeast } & & 0.008 & 0.002 & & 5.370 & 4.400 \\
\hline & & $(0.027)$ & $(0.027)$ & & $(4.207)$ & $(4.288)$ \\
\hline \multirow[t]{2}{*}{ Midwest } & & 0.027 & 0.023 & & $7.304^{*}$ & 6.274 \\
\hline & & $(0.026)$ & $(0.027)$ & & $(4.015)$ & (3.994) \\
\hline \multirow[t]{2}{*}{ South } & & 0.037 & 0.033 & & $6.908^{* *}$ & $5.953^{*}$ \\
\hline & & $(0.024)$ & $(0.023)$ & & $(3.360)$ & $(3.287)$ \\
\hline \multirow[t]{2}{*}{ Father's Education Level $=$ HS } & & & 0.007 & & & 1.969 \\
\hline & & & $(0.024)$ & & & $(3.546)$ \\
\hline \multirow[t]{2}{*}{ Father's Education Level $=$ Some College } & & & 0.021 & & & 3.465 \\
\hline & & & $(0.028)$ & & & $(4.078)$ \\
\hline \multirow[t]{2}{*}{ Mother's Education Level = HS } & & & 0.016 & & & 1.618 \\
\hline & & & $(0.025)$ & & & $(3.539)$ \\
\hline \multirow[t]{2}{*}{ Mother's Education Level $=$ Some College } & & & -0.010 & & & -2.600 \\
\hline & & & $(0.027)$ & & & $(3.887)$ \\
\hline Observations & 522 & 522 & 522 & 522 & 522 & 522 \\
\hline \multicolumn{7}{|l|}{ Test of Hypothesis: } \\
\hline \multicolumn{7}{|l|}{$\mathrm{H}_{\mathrm{o}}: \mathrm{SMEAL}=\mathrm{NSLP}=\mathrm{SNAP}=\mathrm{ALL}=0$} \\
\hline p-value & 0.164 & 0.239 & 0.230 & 0.367 & 0.410 & 0.367 \\
\hline \multicolumn{7}{|l|}{$\mathrm{H}_{\mathrm{o}}: \mathrm{ALL}=\mathrm{SMEAL}+\mathrm{SNAP}$} \\
\hline p-value & 0.026 & 0.041 & 0.056 & 0.051 & 0.050 & 0.051 \\
\hline
\end{tabular}

Notes: Sample includes respondents 15- to 18-years-old and attending school. Estimation by OLS. Constant not shown. SMEAL equals one for participants in both NSLP and SBP, but not SNAP. ALL equals one for participants in all three programs. Column III also includes mother's and father's age, dummies for whether mother's age and father's age are missing, dummy for parents married and present, dummy for whether marital status of parents is missing, and dummies for whether education dummies for father and mother are missing. Survey weights utilized. Number of observations $=522$. Robust standard errors in parentheses. $* * * \mathrm{p}<0.01, * * \mathrm{p}<0.05, * \mathrm{p}<0.1$. 
Table 3. Determinants of Adolescent Time Allocation

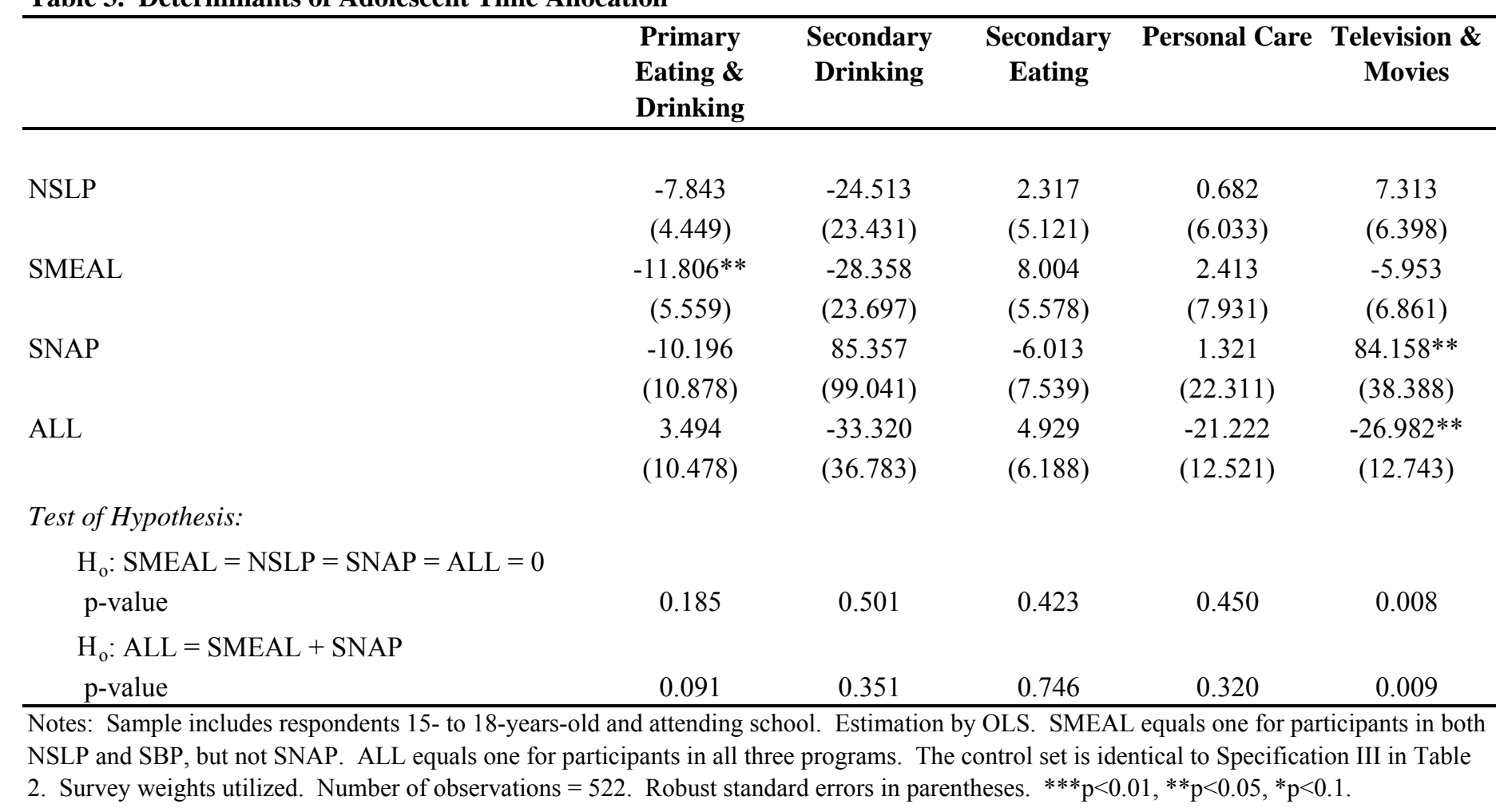


Table 4. Determinants of Adult Time Allocation

\begin{tabular}{|c|c|c|c|c|c|c|c|c|c|}
\hline & $\begin{array}{l}\text { Primary Eating } \\
\text { \& Drinking }\end{array}$ & $\begin{array}{l}\text { Secondary } \\
\text { Eating }\end{array}$ & $\begin{array}{l}\text { Secondary } \\
\text { Drinking }\end{array}$ & $\begin{array}{c}\text { Food } \\
\text { Preparation }\end{array}$ & $\begin{array}{c}\text { Caring For } \\
\text { Household } \\
\text { Children }\end{array}$ & Personal Care & $\begin{array}{l}\text { Television \& } \\
\text { Movies }\end{array}$ & $\begin{array}{c}\text { Grocery } \\
\text { Shopping } \\
\text { (Including Travel } \\
\text { Time) }\end{array}$ & $\begin{array}{c}\text { Grocery } \\
\text { Shopping }>0 \\
\text { (Including Travel } \\
\text { Time) }\end{array}$ \\
\hline \multicolumn{10}{|c|}{ Panel A. Households With at Least One Child Between 5 and 18 Years Old } \\
\hline NSLP & $\begin{array}{c}2.279 \\
(2.099)\end{array}$ & $\begin{array}{l}-0.620 \\
(4.348)\end{array}$ & $\begin{array}{c}8.693 \\
(8.480)\end{array}$ & $\begin{array}{c}-0.383 \\
(1.898)\end{array}$ & $\begin{array}{c}7.970 * * * \\
(2.348)\end{array}$ & $\begin{array}{l}3.780 * \\
(2.251)\end{array}$ & $\begin{array}{c}4.884 * * \\
(2.310)\end{array}$ & $\begin{array}{l}-1.496 \\
(1.054)\end{array}$ & $\begin{array}{l}-2.184 \\
(3.390)\end{array}$ \\
\hline SNAP & $\begin{array}{c}-13.624 * * * \\
(5.175)\end{array}$ & $\begin{array}{c}5.994 \\
(19.256)\end{array}$ & $\begin{array}{c}33.323 \\
(34.000)\end{array}$ & $\begin{array}{l}-4.665 \\
(7.757)\end{array}$ & $\begin{array}{l}-2.726 \\
(6.700)\end{array}$ & $\begin{array}{l}-9.795 \\
(6.299)\end{array}$ & $\begin{array}{c}8.564 \\
(6.964)\end{array}$ & $\begin{array}{c}-4.852 * * \\
(2.136)\end{array}$ & $\begin{array}{c}3.961 \\
(9.756)\end{array}$ \\
\hline SNAP \& NSLP & $\begin{array}{c}-11.910 \\
(9.214)\end{array}$ & $\begin{array}{l}-6.017 \\
(8.161)\end{array}$ & $\begin{array}{c}10.116 \\
(27.698)\end{array}$ & $\begin{array}{c}15.988 \\
(12.194)\end{array}$ & $\begin{array}{c}5.724 \\
(9.790)\end{array}$ & $\begin{array}{l}-0.601 \\
(9.492)\end{array}$ & $\begin{array}{l}10.049 \\
(9.355)\end{array}$ & $\begin{array}{l}-3.658 \\
(3.226)\end{array}$ & $\begin{array}{c}8.194 \\
(11.935)\end{array}$ \\
\hline SMEAL & $\begin{array}{l}-3.731 \\
(2.384)\end{array}$ & $\begin{array}{l}-0.296 \\
(5.339)\end{array}$ & $\begin{array}{c}2.056 \\
(9.355)\end{array}$ & $\begin{array}{l}-0.735 \\
(2.463)\end{array}$ & $\begin{array}{c}9.018 * * * \\
(3.044)\end{array}$ & $\begin{array}{c}4.103 \\
(2.933)\end{array}$ & $\begin{array}{l}6.752^{*} \\
(3.829)\end{array}$ & $\begin{array}{c}-3.069 * * * \\
(1.167)\end{array}$ & $\begin{array}{l}-7.231 \\
(4.890)\end{array}$ \\
\hline ALL & $\begin{array}{l}-5.248 \\
(4.767)\end{array}$ & $\begin{array}{l}-3.124 \\
(8.879)\end{array}$ & $\begin{array}{c}13.157 \\
(16.406)\end{array}$ & $\begin{array}{c}3.744 \\
(4.467)\end{array}$ & $\begin{array}{c}16.557 * * * \\
(6.004)\end{array}$ & $\begin{array}{c}-10.116^{*} \\
(5.412)\end{array}$ & $\begin{array}{c}14.711^{* *} \\
(6.901)\end{array}$ & $\begin{array}{l}-0.093 \\
(2.116)\end{array}$ & $\begin{array}{c}4.318 \\
(6.274)\end{array}$ \\
\hline \multicolumn{10}{|l|}{ Test of Hypothesis: } \\
\hline \multicolumn{10}{|c|}{$\mathrm{H}_{\mathrm{o}}: \mathrm{SMEAL}=\mathrm{NSLP}=\mathrm{SNAP}=\mathrm{SNAP} \& \mathrm{NSLP}=\mathrm{ALL}=0$} \\
\hline p-value & 0.015 & 0.974 & 0.799 & 0.679 & 0.001 & 0.030 & 0.073 & 0.061 & 0.525 \\
\hline $\begin{array}{l}\mathrm{H}_{\mathrm{o}}: \mathrm{ALL}=\mathrm{SN} \\
\mathrm{p} \text {-value }\end{array}$ & 0.084 & 0.668 & 0.546 & 0.307 & 0.255 & 0.590 & 0.952 & 0.009 & 0.521 \\
\hline $\begin{array}{l}\mathrm{H}_{\mathrm{o}}: \text { SNAP \& I } \\
\text { p-value }\end{array}$ & 0.957 & 0.568 & 0.459 & 0.142 & 0.967 & 0.631 & 0.770 & 0.477 & 0.674 \\
\hline \multicolumn{10}{|c|}{ Panel B. Households With at Least One Child Between 5 and 10 Years Old } \\
\hline NSLP & $\begin{array}{c}0.872 \\
(2.359)\end{array}$ & $\begin{array}{c}5.019 \\
(4.922)\end{array}$ & $\begin{array}{c}0.652 \\
(10.466)\end{array}$ & $\begin{array}{l}-1.768 \\
(2.471)\end{array}$ & $\begin{array}{l}6.857^{*} \\
(3.725)\end{array}$ & $\begin{array}{c}3.000 \\
(2.976)\end{array}$ & $\begin{array}{c}4.548 \\
(2.867)\end{array}$ & $\begin{array}{l}-0.403 \\
(1.234)\end{array}$ & $\begin{array}{l}-2.381 \\
(4.637)\end{array}$ \\
\hline SNAP & $\begin{array}{c}-13.953 * * \\
(6.072)\end{array}$ & $\begin{array}{c}3.655 \\
(7.447)\end{array}$ & $\begin{array}{c}20.646 \\
(37.251)\end{array}$ & $\begin{array}{l}-2.166 \\
(9.075)\end{array}$ & $\begin{array}{l}-9.420 \\
(8.655)\end{array}$ & $\begin{array}{c}-11.938^{*} \\
(6.672)\end{array}$ & $\begin{array}{c}9.415 \\
(7.568)\end{array}$ & $\begin{array}{c}-5.969 * * * \\
(1.785)\end{array}$ & $\begin{array}{c}-3.971 \\
(10.577)\end{array}$ \\
\hline SNAP \& NSLP & $\begin{array}{l}-10.947 \\
(12.971)\end{array}$ & $\begin{array}{l}12.252 \\
(9.366)\end{array}$ & $\begin{array}{c}33.340 \\
(37.800)\end{array}$ & $\begin{array}{c}5.873 \\
(14.977)\end{array}$ & $\begin{array}{c}2.334 \\
(14.126)\end{array}$ & $\begin{array}{c}2.383 \\
(10.708)\end{array}$ & $\begin{array}{c}10.457 \\
(11.583)\end{array}$ & $\begin{array}{l}-1.005 \\
(4.520)\end{array}$ & $\begin{array}{c}3.703 \\
(12.650)\end{array}$ \\
\hline SMEAL & $\begin{array}{l}-1.878 \\
(2.977)\end{array}$ & $\begin{array}{c}3.431 \\
(4.888)\end{array}$ & $\begin{array}{c}-8.456 \\
(11.203)\end{array}$ & $\begin{array}{l}-4.645 \\
(3.067)\end{array}$ & $\begin{array}{c}2.277 \\
(4.458)\end{array}$ & $\begin{array}{c}2.916 \\
(3.636)\end{array}$ & $\begin{array}{c}2.270 \\
(3.605)\end{array}$ & $\begin{array}{l}-2.138 \\
(1.444)\end{array}$ & $\begin{array}{l}-8.289 \\
(6.600)\end{array}$ \\
\hline ALL & $\begin{array}{l}-2.475 \\
(5.551)\end{array}$ & $\begin{array}{l}12.114 \\
(9.276)\end{array}$ & $\begin{array}{c}25.205 \\
(21.432)\end{array}$ & $\begin{array}{c}0.556 \\
(5.363)\end{array}$ & $\begin{array}{c}9.026 \\
(7.430)\end{array}$ & $\begin{array}{l}-8.763 \\
(6.139)\end{array}$ & $\begin{array}{c}14.190 * * \\
(6.758)\end{array}$ & $\begin{array}{c}0.969 \\
(2.468)\end{array}$ & $\begin{array}{c}6.528 \\
(7.882)\end{array}$ \\
\hline \multicolumn{10}{|l|}{ Test of Hypothesis: } \\
\hline $\mathrm{p}$-value & 0.264 & 0.635 & 0.504 & 0.730 & 0.227 & 0.155 & 0.227 & 0.008 & 0.631 \\
\hline $\begin{array}{l}\mathrm{H}_{\mathrm{o}}: \mathrm{ALL}=\mathrm{SN} \\
\mathrm{p} \text {-value }\end{array}$ & 0.103 & 0.668 & 0.750 & 0.484 & 0.153 & 0.977 & 0.805 & 0.002 & 0.168 \\
\hline $\begin{array}{l}\mathrm{H}_{\mathrm{o}}: \text { SNAP \& I } \\
\text { p-value }\end{array}$ & 0.879 & 0.770 & 0.815 & 0.572 & 0.764 & 0.360 & 0.798 & 0.248 & 0.534 \\
\hline
\end{tabular}

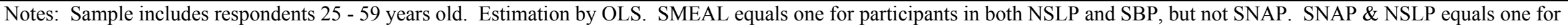

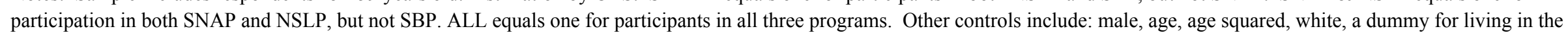
South, education dummies for some college, associate degree, bachelor's degree, MA degree, and for more advanced than a MA degree, and a dummy for being married . Number of

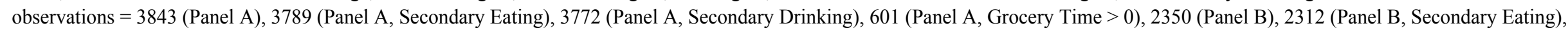
2303 (Panel B, Secondary Drinking), and 349 (Panel B, Grocery Time $>0$ ). Survey weights utilized. Robust standard errors in parentheses. $* * * \mathrm{p}<0.01, * * \mathrm{p}<0.05, * \mathrm{p}<0.1$. 
Table 5. Determinants of Time Allocation

\begin{tabular}{|c|c|c|c|c|c|c|c|c|c|}
\hline & $\begin{array}{l}\text { Primary Eating } \\
\text { \& Drinking }\end{array}$ & $\begin{array}{l}\text { Secondary } \\
\text { Eating }\end{array}$ & $\begin{array}{c}\text { Secondary } \\
\text { Drinking }\end{array}$ & $\begin{array}{c}\text { Food } \\
\text { Preparation }\end{array}$ & $\begin{array}{c}\text { Caring For } \\
\text { Household } \\
\text { Children }\end{array}$ & Personal Care & $\begin{array}{l}\text { Television \& } \\
\text { Movies }\end{array}$ & $\begin{array}{c}\text { Grocery } \\
\text { Shopping } \\
\text { (Including Travel } \\
\text { Time) } \\
\end{array}$ & $\begin{array}{c}\text { Grocery } \\
\text { Shopping }>0 \\
\text { (Including Travel } \\
\text { Time) }\end{array}$ \\
\hline \multicolumn{10}{|c|}{ Panel A. Households With at Least One Child Between 5 and 18 Years Old } \\
\hline NSLP & $\begin{array}{c}0.336 \\
(3.085)\end{array}$ & $\begin{array}{c}-4.892 \\
(5.634)\end{array}$ & $\begin{array}{c}14.753 \\
(13.035)\end{array}$ & $\begin{array}{c}2.241 \\
(2.741)\end{array}$ & $\begin{array}{c}4.233 \\
(3.378)\end{array}$ & $\begin{array}{c}1.629 \\
(3.418)\end{array}$ & $\begin{array}{l}8.684 * * \\
(3.374)\end{array}$ & $\begin{array}{c}-2.077 \\
(1.712)\end{array}$ & $\begin{array}{l}-4.285 \\
(5.460)\end{array}$ \\
\hline SNAP & $\begin{array}{c}-14.591 * * * \\
(5.566)\end{array}$ & $\begin{array}{c}5.925 \\
(20.818)\end{array}$ & $\begin{array}{c}41.492 \\
(37.075)\end{array}$ & $\begin{array}{l}-4.680 \\
(8.290)\end{array}$ & $\begin{array}{l}-8.778 \\
(6.393)\end{array}$ & $\begin{array}{l}-8.649 \\
(6.931)\end{array}$ & $\begin{array}{l}12.441 * \\
(7.356)\end{array}$ & $\begin{array}{l}-6.214^{* *} \\
(2.503)\end{array}$ & $\begin{array}{c}-7.087 \\
(11.517)\end{array}$ \\
\hline SNAP \& NSLP & $\begin{array}{c}-23.994 * * * \\
(6.670)\end{array}$ & $\begin{array}{l}-8.071 \\
(8.955)\end{array}$ & $\begin{array}{c}21.601 \\
(32.912)\end{array}$ & $\begin{array}{c}12.275 \\
(12.000)\end{array}$ & $\begin{array}{l}-3.708 \\
(8.578)\end{array}$ & $\begin{array}{c}0.809 \\
(10.277)\end{array}$ & $\begin{array}{c}12.528 \\
(10.777)\end{array}$ & $\begin{array}{l}-3.710 \\
(4.073)\end{array}$ & $\begin{array}{c}3.640 \\
(14.875)\end{array}$ \\
\hline SMEAL & $\begin{array}{l}-4.634 \\
(3.269)\end{array}$ & $\begin{array}{l}-4.353 \\
(6.530)\end{array}$ & $\begin{array}{c}-4.744 \\
(11.772)\end{array}$ & $\begin{array}{c}0.190 \\
(3.185)\end{array}$ & $\begin{array}{l}7.356^{*} \\
(4.133)\end{array}$ & $\begin{array}{c}5.001 \\
(3.880)\end{array}$ & $\begin{array}{c}7.057 \\
(5.295)\end{array}$ & $\begin{array}{c}-3.761 * * \\
(1.707)\end{array}$ & $\begin{array}{l}-11.245 \\
(7.059)\end{array}$ \\
\hline ALL & $\begin{array}{l}-5.774 \\
(4.925)\end{array}$ & $\begin{array}{l}-3.439 \\
(9.958)\end{array}$ & $\begin{array}{c}11.654 \\
(18.416)\end{array}$ & $\begin{array}{c}4.188 \\
(4.806)\end{array}$ & $\begin{array}{c}14.327 * * \\
(6.535)\end{array}$ & $\begin{array}{c}-10.282 * \\
(5.890)\end{array}$ & $\begin{array}{c}15.246^{* *} \\
(7.465)\end{array}$ & $\begin{array}{l}-1.745 \\
(2.391)\end{array}$ & $\begin{array}{l}-1.128 \\
(7.665)\end{array}$ \\
\hline \multicolumn{10}{|l|}{ Test of Hypothesis: } \\
\hline $\begin{array}{l}\mathrm{H}_{\mathrm{o}}: \mathrm{SMEAL}= \\
\mathrm{p} \text {-value }\end{array}$ & $\begin{array}{c}\text { AP \& NSLP }= \\
0.001\end{array}$ & $\begin{array}{l}\mathrm{LL}=0 \\
0.912\end{array}$ & 0.476 & 0.737 & 0.028 & 0.110 & 0.053 & 0.135 & 0.691 \\
\hline $\begin{array}{l}\mathrm{H}_{\mathrm{o}}: \mathrm{ALL}=\mathrm{SN} \\
\mathrm{p} \text {-value }\end{array}$ & 0.066 & 0.825 & 0.528 & 0.367 & 0.095 & 0.460 & 0.704 & 0.018 & 0.244 \\
\hline $\begin{array}{l}\mathrm{H}_{\mathrm{o}}: \text { SNAP \& I } \\
\text { p-value }\end{array}$ & 0.259 & 0.670 & 0.475 & 0.310 & 0.937 & 0.527 & 0.510 & 0.331 & 0.423 \\
\hline \multicolumn{10}{|c|}{ Panel B. Households With at Least One Child Between 5 and 10 Years Old } \\
\hline NSLP & $\begin{array}{l}-2.745 \\
(3.619)\end{array}$ & $\begin{array}{l}-4.762 \\
(6.039)\end{array}$ & $\begin{array}{c}-5.234 \\
(17.248)\end{array}$ & $\begin{array}{l}-0.296 \\
(3.673)\end{array}$ & $\begin{array}{c}3.873 \\
(5.327)\end{array}$ & $\begin{array}{l}-1.351 \\
(4.306)\end{array}$ & $\begin{array}{c}6.246 \\
(4.434)\end{array}$ & $\begin{array}{c}-2.954 \\
(1.929)\end{array}$ & $\begin{array}{l}-11.882 \\
(8.034)\end{array}$ \\
\hline SNAP & $\begin{array}{c}-18.407 * * * \\
(6.588)\end{array}$ & $\begin{array}{c}1.554 \\
(9.013)\end{array}$ & $\begin{array}{c}22.569 \\
(42.238)\end{array}$ & $\begin{array}{l}-2.075 \\
(9.835)\end{array}$ & $\begin{array}{c}-16.128^{*} \\
(8.226)\end{array}$ & $\begin{array}{l}-11.305 \\
(7.462)\end{array}$ & $\begin{array}{l}10.731 \\
(8.156)\end{array}$ & $\begin{array}{c}-7.795 * * * \\
(2.238)\end{array}$ & $\begin{array}{l}-14.304 \\
(11.891)\end{array}$ \\
\hline SNAP \& NSLP & $\begin{array}{c}-33.256 * * * \\
(8.427)\end{array}$ & $\begin{array}{c}9.209 \\
(10.281)\end{array}$ & $\begin{array}{c}48.824 \\
(47.610)\end{array}$ & $\begin{array}{c}-2.056 \\
(13.241)\end{array}$ & $\begin{array}{c}-9.995 \\
(13.138)\end{array}$ & $\begin{array}{c}4.885 \\
(11.386)\end{array}$ & $\begin{array}{c}12.887 \\
(14.595)\end{array}$ & $\begin{array}{l}-0.070 \\
(6.066)\end{array}$ & $\begin{array}{c}0.119 \\
(13.063)\end{array}$ \\
\hline SMEAL & $\begin{array}{l}-5.609 \\
(4.042)\end{array}$ & $\begin{array}{l}-0.907 \\
(6.809)\end{array}$ & $\begin{array}{l}-24.009 \\
(15.516)\end{array}$ & $\begin{array}{l}-4.098 \\
(4.014)\end{array}$ & $\begin{array}{c}1.354 \\
(6.032)\end{array}$ & $\begin{array}{c}1.840 \\
(4.305)\end{array}$ & $\begin{array}{l}-1.407 \\
(4.871)\end{array}$ & $\begin{array}{l}-2.444 \\
(2.133)\end{array}$ & $\begin{array}{l}-12.737 \\
(9.490)\end{array}$ \\
\hline ALL & $\begin{array}{l}-6.912 \\
(5.603)\end{array}$ & $\begin{array}{c}12.852 \\
(11.280)\end{array}$ & $\begin{array}{c}20.759 \\
(24.902)\end{array}$ & $\begin{array}{c}0.151 \\
(5.802)\end{array}$ & $\begin{array}{c}6.004 \\
(8.254)\end{array}$ & $\begin{array}{l}-8.936 \\
(6.352)\end{array}$ & $\begin{array}{l}10.869 \\
(7.519)\end{array}$ & $\begin{array}{c}0.126 \\
(2.856)\end{array}$ & $\begin{array}{l}-2.372 \\
(9.655)\end{array}$ \\
\hline \multicolumn{10}{|l|}{ Test of Hypothesis: } \\
\hline p-value & 0.001 & 0.518 & 0.106 & 0.942 & 0.192 & 0.367 & 0.274 & 0.007 & 0.573 \\
\hline $\begin{array}{l}\mathrm{H}_{\mathrm{o}}: \mathrm{ALL}=\mathrm{SN} \\
\mathrm{p} \text {-value }\end{array}$ & 0.045 & 0.381 & 0.626 & 0.582 & 0.079 & 0.957 & 0.888 & 0.004 & 0.128 \\
\hline $\begin{array}{l}\mathrm{H}_{\mathrm{o}}: \text { SNAP \& I } \\
\text { p-value }\end{array}$ & 0.248 & 0.345 & 0.606 & 0.985 & 0.884 & 0.199 & 0.804 & 0.088 & 0.139 \\
\hline
\end{tabular}

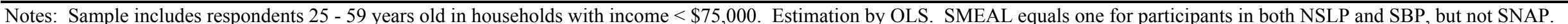

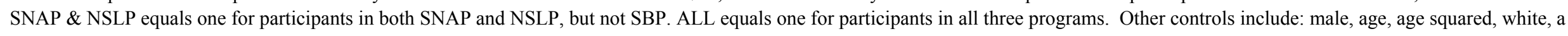

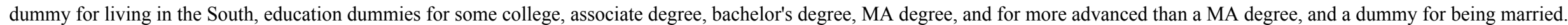

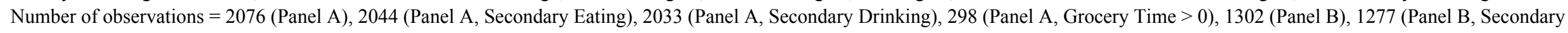

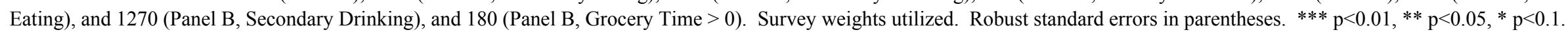

